Orbital modulation of AMOC variability

T. Friedrich et al.

\section{Orbital modulation of millennial-scale climate variability in an earth system model of intermediate complexity}

\author{
T. Friedrich ${ }^{1}$, A. Timmermann ${ }^{1}$, L. Menviel ${ }^{1}$, O. Timm ${ }^{1}$, A. Mouchet ${ }^{2}$, and \\ D. M. Roche ${ }^{3}$
}

${ }^{1}$ IPRC, University of Hawaii, 2525 Correa Road, Honolulu, HI 96822, USA

${ }^{2}$ Département Astrophysique, Géophysique et Océanographie, Université de Liège, Liège, Belgium

${ }^{3}$ Section Climate Change and Landscape Dynamics, Department of Earth Sciences, Vrije Universiteit Amsterdam, De Boelelaan 1085, 1081 HV Amsterdam, The Netherlands

Received: 1 July 2009 - Accepted: 22 July 2009 - Published: 28 July 2009

Correspondence to: T. Friedrich (tobiasf@ hawaii.edu)

Published by Copernicus Publications on behalf of the European Geosciences Union.

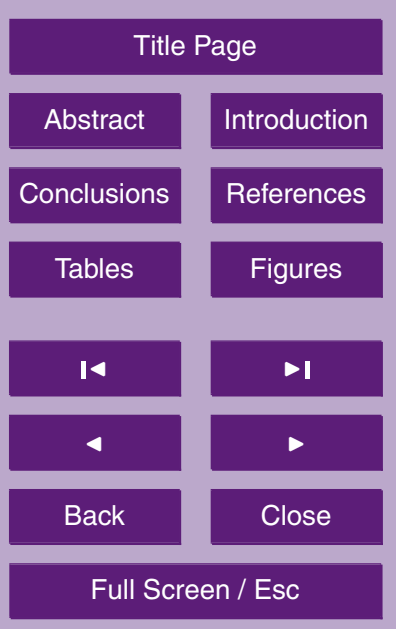

Printer-friendly Version

Interactive Discussion 


\section{Abstract}

The effect of orbital variations on simulated millennial-scale variability of the Atlantic Meridional Overturning Circulation (AMOC) is studied using the earth system model of intermediate complexity LOVECLIM. It is found that for present-day topographic bound-

5 ary conditions low obliquity values $\left(\sim 22.1^{\circ}\right)$ favor the triggering of internally generated millennial-scale variability in the North Atlantic region. Reducing the obliquity leads to changes of the pause-pulse ratio of the corresponding AMOC oscillations. Stochastic excitations of the density-driven overturning circulation in the Nordic Seas can create regional sea-ice anomalies and a subsequent reorganization of the atmospheric circu10 lation. The resulting remote atmospheric anomalies over the Hudson Bay can release freshwater pulses into the Labrador Sea leading to a subsequent reduction of convective activity. The millennial-scale AMOC oscillations disappear if LGM bathymetry (with closed Hudson Bay) is prescribed. Furthermore, our study documents the marine and terrestrial carbon cycle response to millennial-scale AMOC variability. Our model re15 sults support the notion that stadial regimes in the North Atlantic are accompanied by relatively high levels of oxygen in thermocline and intermediate waters off California in agreement with paleo-proxy data.

\section{Introduction}

Oxygen isotope records from Greenland (Johnsen et al., 1992; Dansgaard, 1993; GRIP

Project Members, 1993; NGRIP Project Members, 2004) bear witness to the existence of abrupt climate reorganizations in the Northern Hemisphere. Dansgaard-Oeschger (DO) events (Dansgaard et al., 1982; Oeschger et al., 1984), i.e. rapid transitions from stadial to interstadial conditions, are prominent features of the last glacial period. Their abruptness has prompted researchers to hypothesize that their dynamics is tightly coupled to the Atlantic Meridional Overturning Circulation (AMOC) (Ganopolski et al., 1998; Alley et al., 2001; Timmermann et al., 2003). In simplified and intermedi-

\section{5, 2019-2051, 2009}

Orbital modulation of AMOC variability

T. Friedrich et al.

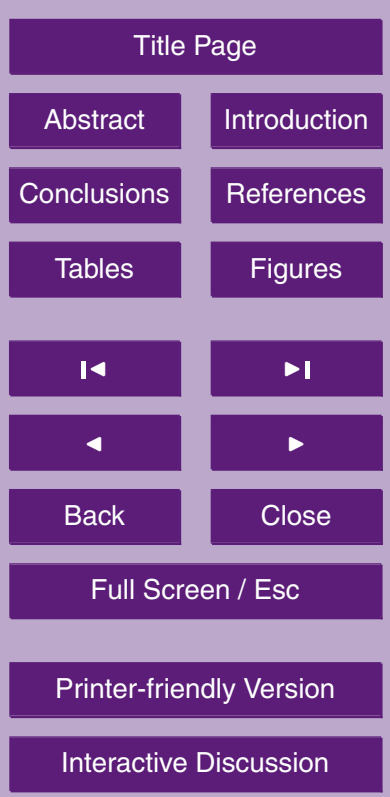


ate complexity models (Stommel, 1961; Broecker et al., 1990; Ganopolski et al., 1998) the AMOC is known to exhibit multiple equilibrium solutions due to the nonlinearity of meridional density advection. Stochastic and periodic excitation of such a bistable system can generate dynamical behavior that resembles the observed DO events (Alley 5 et al., 2001).

However, recent coupled general circulation modeling (CGCM) studies (Liu et al., 2009 , in press) have demonstrated that the simulated hysteresis behavior of the AMOC with respect to freshwater forcing (an indicator for the existence of multiple equilibria) is weaker than previously thought. While the jury is still out, other dynamical concepts are being considered to explain the emergence of DO events under glacial conditions.

In fact, the observed DO events bear some similarity to the so-called ocean relaxation oscillations. Their mechanism involves a long "recharging" timescale, often associated with advective or diffusive processes and a rapid "flushing" process, such as oceanic convection. Internally generated centennial to millennial-scale relaxation oscillations of the AMOC have been simulated in ocean and climate models of varying complexity (Winton, 1993; Winton and Sarachik, 1993; Paul and Schulz, 2002; Timmermann and Goosse, 2004; Rial and Yang, 2007; Schulz et al., 2007; Jongma et al., 2007; Rial and Saha, 2008) and have often been explained in terms of the deepdecoupling oscillation concept (Winton, 1993). The deep-decoupling phase of such an oscillation describes a state with little North Atlantic deep-water formation (due to reduced surface densities). Under such conditions subsurface advective or diffusive heating can lead to a de-stabilization of the water column in the convective areas of the North Atlantic and eventually a convective flush that enhances North Atlantic Deep Water Formation and the meridional overturning circulation. Such flushes are associated with increased poleward heat transport that may provide a self-limiting negative feedback to the AMOC. The relaxation oscillation framework is fundamentally different from the multiple equilibrium framework described in (Stommel, 1961; Broecker et al., 1990; Ganopolski et al., 1998) and adopted frequently to explain abrupt climate change.

Several modeling studies (Aeberhardt et al., 2000; Ganopolski and Rahmstorf, 2002;

Orbital modulation of AMOC variability

T. Friedrich et al.

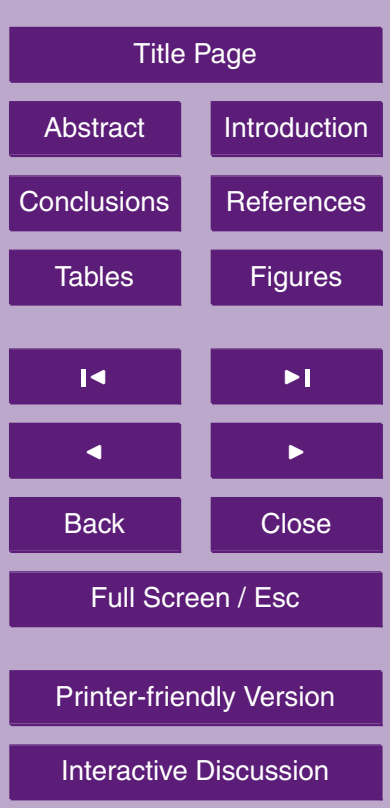

2021 
Timmermann et al., 2003; Schulz et al., 2007) have demonstrated that stochastic forcing can facilitate the excitation of nonlinear relaxation oscillations of the AMOC. In contrast to the classical multiple-equilibrium stochastic resonance (SR) framework for DO events proposed by Alley et al. (2001), the stochastic excitation of subthreshold 5 relaxation-oscillations (the so-called coherence resonance (CR) (Pikovsky and Kurths, 1997)) relies on the co-existence of a limit cycle and an unstable equilibrium point in a relevant range of the parameter space of the system. In the presence of external periodic forcing SR and CR behave very differently. In the classical SR case, external forcing modulates the hopping probability from one equilibrium point to the other. For $10 \mathrm{CR}$, external forcing can phase-synchronize the stochastically excited internal mode of nonlinear variability (Timmermann et al., 2003).

Adopting such idealized dynamical systems' concepts to the climate record of the last 100000 years confronts us with a major problem: the characteristics of DO variability have undergone significant low-frequency changes. Orbital forcing is a likely candidate to modulate features of millennial-scale climate variability during the last glacial period. This has recently been confirmed by idealized modeling studies (Rial and Yang, 2007; Rial and Saha, 2008). Using the earth system model of intermediate complexity ECBilt-CLIO, the authors found that Greenland ice-core data can be interpreted in terms of a frequency modulated relaxation oscillation. According to their hypothesis internally generated deep-decoupling oscillations in the North Atlantic become frequency modulated by orbitally-induced changes of the solar radiation.

Inspired by their findings and the Schulz et al. (2007) and Jongma et al. (2007) study, we set forth to further elucidate the physical mechanisms responsible for the generation of millennial-scale climate variability in the ECBilt-CLIO climate model.

This paper is organized as follows: After a brief description of the model and the experiments in the subsequent two Sects. 2 and 3, we describe the main results from a suite of climate sensitivity experiments in Sect. 4. In Sect. 5 we discuss and summarize the main implications of our findings.
5, 2019-2051, 2009

Orbital modulation of AMOC variability

T. Friedrich et al.

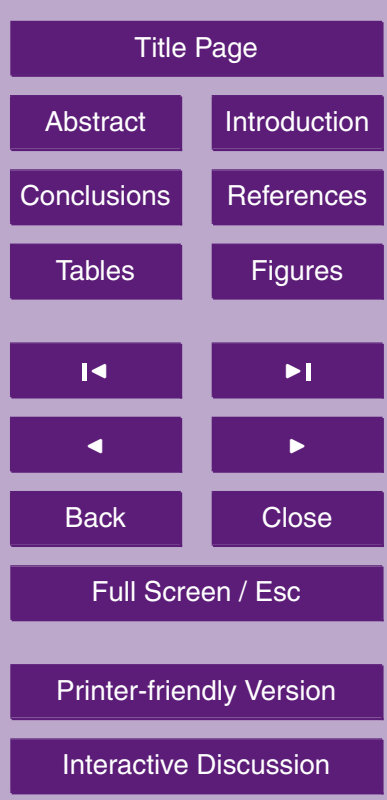

Interactive Discussion

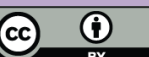




\section{Model configuration}

To quantify the effects of orbital forcing on the dynamics of the AMOC we conducted a series of climate sensitivity experiments using the atmosphere-ocean-sea ice-carbon cycle model LOVECLIM (Driesschaert, 2005). LOVECLIM is based on the ECBilt-CLIO 5 EMIC extended by vegetation and marine carbon cycle components.

Its sea ice-ocean component (CLIO) (Goosse et al., 1999) consists of a primitive equation level model with $3^{\circ} \times 3^{\circ}$ resolution on a partly rotated grid in the North Atlantic. CLIO uses a free surface and is coupled to a thermodynamic-dynamic sea ice model. In the vertical there are 20 unevenly spaced levels with a thickness ranging from $10 \mathrm{~m}$

10 near the surface to $\sim 700 \mathrm{~m}$ below $3000 \mathrm{~m}$. Mixing along isopycnals, vertical mixing as well as the effect of mesoscale eddies on transports and mixing and downsloping currents at the bottom of continental shelfs are parametrized. The Bering Strait is closed in our simulations which inhibits freshwater transport from the Pacific into the Arctic.

15 The atmosphere model (ECBilt) is a spectral T21, based on quasigeostrophic equations with 3 vertical levels and a horizontal resolution of about $5.625^{\circ} \times 5.625^{\circ}$. Ageostrophic forcing terms are estimated from the vertical motion field and added to the prognostic vorticity equation and thermodynamic equation. Diabatic heating due to radiative fluxes, the release of latent heat and the exchange of sensible heat with the surface are parametrized. The seasonally and spatially varying cloud cover climatology is prescribed in ECBilt.

The ocean, atmosphere and sea ice component of the ECBilt-CLIO model are coupled by exchange of momentum, heat and freshwater fluxes. The hydrological cycle over land is closed by a bucket model for soil moisture and simple river runoff scheme.

25 A small correction for freshwater flux is prescribed redirecting snow- and rainfall over the Atlantic to the North Pacific.

The terrestrial vegetation module of LOVECLIM, VECODE is described by Brovkin et al. (1997). On the basis of annual mean values of several climatic variables, the

Orbital modulation of AMOC variability

T. Friedrich et al.
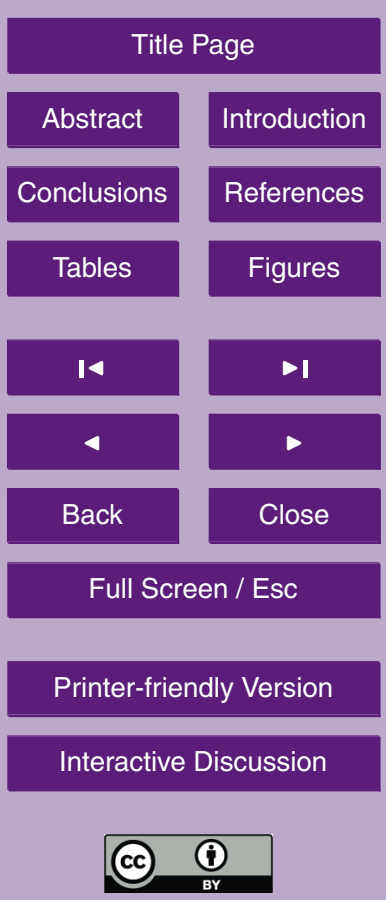
VECODE model computes the evolution of the vegetation cover described as a fractional distribution of desert, tree, and grass in each land grid cell once a year. Within the LOVECLIM version used here, simulated vegetation changes affect only the land surface albedo, and have no influence on other processes such as evapotranspiration 5 or surface roughness.

$\mathrm{LOCH}$ is a three-dimensional global model of the oceanic carbon cycle with prognostic equations for dissolved inorganic carbon, total alkalinity, phosphate, organic products, oxygen and silicates (Mouchet and Francois, 1996; Menviel et al., 2008a,b). $\mathrm{LOCH}$ is coupled to CLIO, using the same time step. Biogeochemical tracers in LOCH 10 are advected with the CLIO circulation field and are subject to horizontal and vertical mixing. The near-surface oceanic uptake of $\mathrm{CO}_{2}$ is governed by the solubility as well as the regional biological processes. The partial pressure of $\mathrm{CO}_{2}\left(p \mathrm{CO}_{2}\right)$ in the surface waters is calculated from the total alkalinity and dissolved inorganic carbon. The difference between the $\mathrm{pCO}_{2}$ in the ocean and in the atmosphere, modulated by a 15 wind-dependent exchange coefficient, determines the net $\mathrm{CO}_{2}$ air-sea fluxes. $\mathrm{LOCH}$ computes the export production from the state of a phytoplankton pool in the euphotic zone $(0-120 \mathrm{~m})$. The phytoplankton growth depends on the availability of nutrients (phosphate) and light, with a weak temperature dependence. A grazing process together with natural mortality limit the primary production and provide the source term for the organic matter sinking to depth. Remineralization of organic matter depends on oxygen availability, but anoxic remineralization can also occur. Depending on the silica availability, phytoplankton growth is accompanied by the formation of opal or $\mathrm{CaCO}_{3}$ (calcite and aragonite) shells, which then sink to depth. These shells are dissolved depending on the calcite and aragonite saturation states, whereas a simple constant rate is used for opal. The organic matter that is not remineralized and the shells that are not dissolved are permanently preserved in the sediments. The associated loss of alkalinity, carbon, phosphates and silicates, is balanced by the river influx of these components. The atmospheric $\mathrm{CO}_{2}$ content is predicted for each ocean time step from the air-sea $\mathrm{CO}_{2}$ fluxes calculated by $\mathrm{LOCH}$ as well as from the air-terrestrial biomass

5, 2019-2051, 2009

Orbital modulation of AMOC variability

T. Friedrich et al.

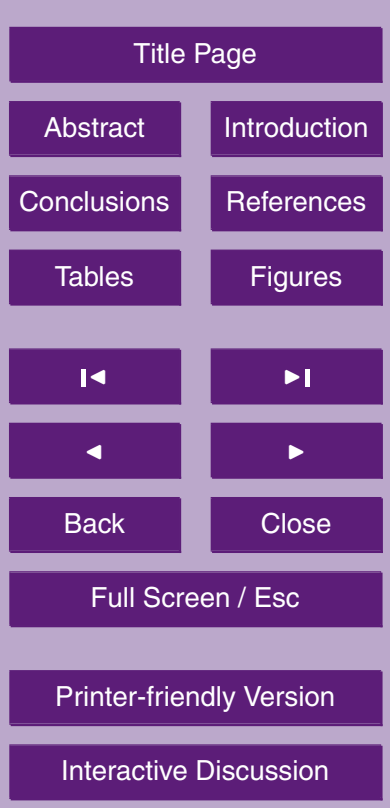

2024 


\section{Experiments}

A set of experiments was conducted to study the effect of changes in earth's obliquity on the internally generated low frequency variability of the AMOC (Table 1). A 5 pre-industrial baseline simulation was obtained with LOVECLIM by first prescribing present-day orbital parameters, bathymetry, land albedo and topography and by forcing the model with an atmospheric $\mathrm{CO}_{2}$ concentration of 287 ppmv for 500 years. Thereafter by activating the coupling between the carbon cycle and the climate components, the atmospheric $\mathrm{CO}_{2}$ concentrations are allowed to vary freely for another 1700 years.

10 The mean climate of the baseline run was described in (Menviel et al., 2008a). A new control run (CTR, in Table 1) was integrated from this equilibrium for 8000 years. Subsequently, 3 model runs were conducted for 5000 year using obliquity values of $22.8^{\circ}$, $22.4^{\circ}$ and $22.1^{\circ}$ and keeping pre-industrial values for all other boundary conditions (see Table 1). In addition, a 2000 year-long sensitivity run was performed with LOVECLIM using LGM-bathymetry values (Roche et al., 2007) and an obliquity value of $22.1^{\circ}$.

In the present study the model is exclusively forced by different obliquity values. No use has been made of additional constant (Schulz et al., 2007) or time-varying (Ganopolski et al., 1998) freshwater perturbations.

\section{Results}

\section{$20 \quad$ 4.1 AMOC response to obliquity forcing}

The climatological formation sites of North Atlantic Deep Water in our model are located in the eastern Greenland Iceland Norway (GIN) Sea, in the Labrador Sea and Irminger Sea. The meridional streamfunction of the CTR run that characterizes the Atlantic

Orbital modulation of AMOC variability

T. Friedrich et al.

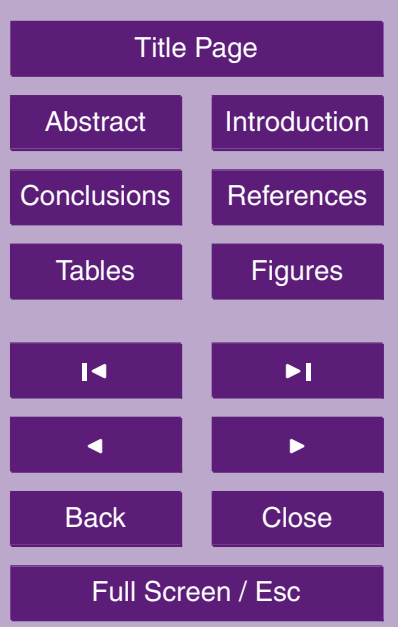

Printer-friendly Version

Interactive Discussion 
meridional overturning circulation (Fig. 1) exhibits the two main deepwater formation branches: one north and one south of the Greenland-Scotland Ridge.

Figure 2 compares the simulated variations in the GIN Sea overturning circulation (GSOC) (see Fig. 1) and the maximum of the AMOC (including the GIN Sea; in the 5 following simply referred to as the AMOC index) for the control run (CTR) and the three obliquity runs (OBL22.8, OBL22.4, OBL22.1). Here we define the GSOC index as the maximum value of the meridional stream function north of the Greenland-Scotland Ridge, whereas the AMOC index refers to the overall maximum of the streamfunction in the North Atlantic.

10 For both indeces an increase in the level of internally generated centennial-tomillennial scale variability can be seen for decreasing values of obliquity. For obliquity values of $22.8^{\circ}$ we observe an enhanced level of low-frequency variability in the GSOC index. However, similar changes in the AMOC strength are absent for this obliquity value. The situation changes drastically for obliquity values of $22.4^{\circ}$ : GSOC

varies by about $\pm 2.5 \mathrm{~Sv}$ and these variations are accompanied by abrupt transitions between a strong AMOC state ( 26 Sv) and an intermediate state ( 17 Sv) (Fig. 2g). The timescale of this variability ranges from 1000-1500 years. Further reduction of the obliquity to $22.1^{\circ}$ (Fig. 2h) leads to a shift of the pause-pulse ratio: The AMOC is now preferentially operating in the intermediate regime, rather than in the strong AMOC 20

state. Similar changes of the pause-pulse ratio of millennial-scale AMOC variability can be induced by external freshwater forcing, as described in the idealized box-modeling study of Schulz et al. (2002) and the LOVECLIM modeling study of Schulz et al. (2007) and Jongma et al. (2007). The resulting dynamics and the presence of an intermediate AMOC state for OBL22.4 and OBL22.1 are reminiscent of the existence of an AMOC 25 limit cycle (Timmermann et al., 2003).

\subsection{Mechanism of millennial-scale AMOC variability}

To elucidate the physical mechanisms responsible for the generation of millennial-scale GSOC and AMOC variability, we focus on only one event in the OBL22.4 run (model 2026
5, 2019-2051, 2009

Orbital modulation of AMOC variability

T. Friedrich et al.

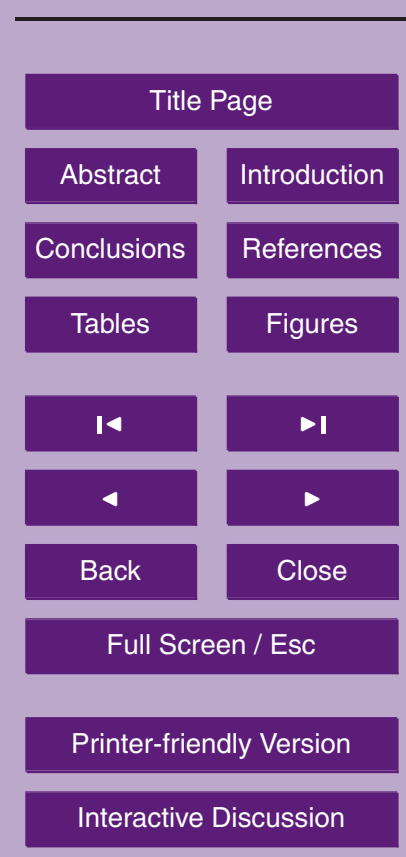

Interactive Discussion

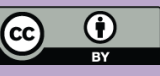


years 2450-3050). Further statistical analysis (not shown) revealed that the same mechanism operates in the other experiments and for other individual events.

Figures 3b-g document crucial stages during an AMOC cycle in the OBL22.4 experiment as well as the associated states of the two overturning cells (Fig. 3a). In our sim5 ulation an event is initiated by a random reduction of the GSOC. This reduction leads to a decrease of meridional heat transport into the GIN Sea and an associated decline in SST in the sinking region of $\sim 2-5 \mathrm{~K}$ (not shown). The drop in SST causes an increase in sea ice coverage in the considered region (not shown). The position of the sea ice margin $^{1}$ shifts southward by several degrees latitude, now covering the major part of 10 the sinking region. Sea ice insulates the ocean surface from heat loss which leads to a further reduction of the strength of the overturning (Fig. 3b). As a consequence of the sea-ice expansion, surface air temperature (SAT) decreases in the Nordic Seas by up to $20 \mathrm{~K}$ (Fig. 3c). The resulting geopotential height anomaly over the eastern North Atlantic exhibits a baroclinic structure in the vertical similar to the response to negative 15 SST anomalies in Deser et al. (2004). A surface boundary layer high pressure anomaly develops over the GIN Sea that is accompanied by low pressure anomalies over southern Greenland and the Hudson Bay (Fig. 3c). As we shall see later the resulting wind stress anomalies over the Hudson Bay are crucial for the reduction of Labrador Sea convection and eventually the weakening of the AMOC. Due to the model representa20 tion of river runoff, sea surface salinity (SSS) in the Hudson Bay is about 1.4 psu lower ( $\sim 33.60 \mathrm{psu})$ than in the adjacent Labrador Sea ( 34.98 psu) - in accordance with the Levitus Climatology (Levitus, 1994). Under climatological conditions the zonal salinity gradient between Hudson Bay and Labrador Sea is maintained by north-westerly winds. As a result of the altered near surface pressure pattern (Fig. 3c), wind stress 25 near Hudson Strait changes its direction which results in a flush of fresher water from the Hudson Bay into the Labrador Sea (Fig. 3c, d). Moreover, the anomalous low pressure near Hudson Bay leads to a significant increase in snow fall further freshening surface waters (not shown). The resulting drop of SSS in the Labrador Sea (Fig. 3d)

\footnotetext{
${ }^{1}$ defined here as the position of the $0.1 \mathrm{~m}$ sea ice thickness contour
}

Orbital modulation of AMOC variability

T. Friedrich et al.

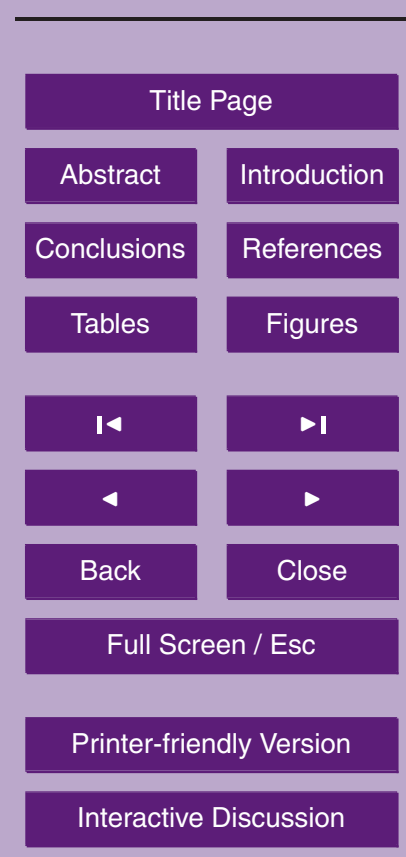

2027 
leads to a major reduction of Labrador Sea convection and a subsequent decrease of the North Atlantic overturning circulation strength by about $8 \mathrm{~Sv}$ (Fig. 3a-phase d). A part of this fresh surface water is advected from the Labrador Sea into the GIN Sea, thereby maintaining the halocline in the GIN Sea. In OBL22.4 this state of reduced 5 overturning lasts for about 300 years. Anomalies in the annual mean convective layer depth (CLD) attain values of up to $-200 \mathrm{~m}$ in the Labrador Sea and up to $-400 \mathrm{~m}$ in the GIN Sea ${ }^{2}$. The atmospheric response pattern to the GIN Sea near-surface temperature anomalies is persistent throughout the entire period of AMOC weakening (Fig. 3e). The recovery phase of the AMOC (Fig. $3 \mathrm{f}, \mathrm{g}$ ) is associated with subsurface warming of 10 the GIN Sea (Fig. 3f). Subsurface temperature anomalies in this region reach values of up to $4 \mathrm{~K}$. Compared to the unperturbed variance of subsurface temperature variations of $0.26 \mathrm{~K}$, a $4 \mathrm{~K}$ anomaly during the recovery phase represents an unprecedented warming of the subsurface and deep-water layers - a phenomenon known as deep decoupling. Even though GSOC is strongly reduced in phase e, $f$ (see Fig. 3a), warm and salty water from the North Atlantic Drift is still advected into the Nordic Seas and the Arctic at depths of 500-1500 m. Due to the lack of deep ocean convection, the inflowing warm and salty North Atlantic waters are not mixed with colder surface waters anymore. The subsurface temperatures in the GIN Sea become decoupled from the surface processes and begin to increase (Fig. 3f). The increase of subsurface heat 20 content eventually reduces the vertical density gradient to a point when surface convection is re-initiated (Fig. $3 \mathrm{~g}$ ) with the help of random surface flux variations. Previously stored subsurface heat is vented to the surface. Sea-ice coverage reduces and surface air temperature increases by up to $10 \mathrm{~K}$. Associated atmospheric circulation changes generate surface wind anomalies near Hudson Bay, a reduction of snow fall in that area and a re-establishment of the original zonal salinity gradient between the Hudson Bay and the Labrador Sea. These processes initiate the recovery of the AMOC.

\footnotetext{
${ }^{2}$ In wintertime these anomalies are much larger
}

5, 2019-2051, 2009

Orbital modulation of AMOC variability

T. Friedrich et al.

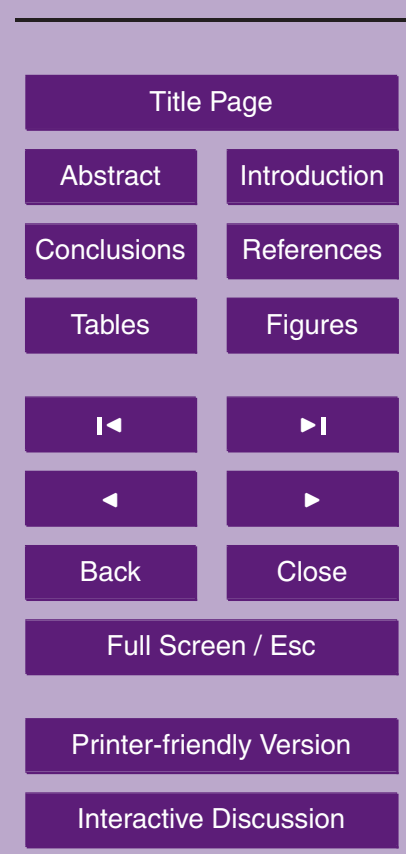

2028 


\subsection{Orbital effects on AMOC variability}

In our model simulations a close connection between AMOC stability and obliquity becomes apparent (Fig. 2) that requires further explanation. Figure 4 shows the relationship between the simulated variance of millennial-scale GSOC variations and a 5 suite of relevant oceanographic variables in the Nordic Seas averaged for a strong GSOC state as a function of the obliquity forcing. We observe a pronounced increase of surface density in the Arctic with decreasing obliquity (Fig. 4a). Low obliquity values are associated with reduced seasonality, hence allowing for more annual sea ice build-up due to lower summer temperatures (Fig. 4c). This leads to an increase in 10 Arctic surface salinity (Fig. 4b) and a decrease in SAT due to an ice-albedo feedback (Fig. 4d). In concert with increased upper ocean Arctic salinity and density, the annual mean convective layer depth in the GIN Sea sinking region also increases (Fig. 4e). Changing obliquity from $23.446^{\circ}$ (present-day value) to $22.1^{\circ}$ leads to an increase of centennial to millennial-scale GSOC variations (Fig. 2a-d).

Figure 5 demonstrates why lower obliquity values may enhance GSOC variability during a strong GSOC state: a randomly occurring negative GSOC anomaly reduces poleward heat transport into the sinking regions. The resulting local increase of seaice depends on the prevailing obliquity. With lower obliquity values and hence colder summers there is a greater chance for the sea-ice anomaly to persist into the winter season. This leads to a reduction of air-sea fluxes and eventually an amplification of the negative GSOC anomaly. If these anomalies persist, the resulting atmospheric response (Fig. 3c) can trigger flushes of fresh water from the Hudson Bay into the Labrador Sea. Reduced formation of Labrador Sea Water leads to a major reduction of the AMOC. Therefore, obliquity forcing plays a crucial role in modulating the strength of 25 the positive feedback between sea-ice and convection in the GIN Sea with subsequent effects on GSOC and AMOC.
5, 2019-2051, 2009

Orbital modulation of AMOC variability

T. Friedrich et al.

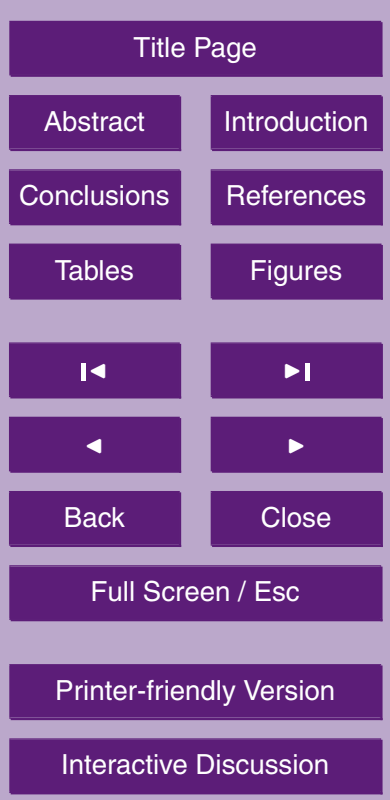

Interactive Discussion 


\subsection{Sensitivity experiments}

To further elucidate what physical processes are responsible for the generation of simulated millennial-scale AMOC variability a series of sensitivity experiments was conducted. A key component of the proposed mechanism (Sect. 4.2) is the large-scale

5 atmospheric response to GIN Sea temperature anomalies, which plays a fundamental role in flushing Hudson Bay freshwater anomalies into the Labrador Sea and hence in weakening the AMOC.

Here, we will address the question whether the simulated atmospheric anomaly pattern (Fig. $3 \mathrm{c}$ ) is a consequence of the initial GSOC weakening and how it interacts with 10 the latter.

We repeated the OBL22.4 run starting from a strong AMOC state. In the first 50 model years a sea surface temperature (SST) climatology was generated. Subsequently this climatology was applied for 200 model years everywhere as a lower boundary conditions for the atmospheric model, except for the GIN Sea, where simulated 15 temperatures were lowered artificially by lowering SST (as seen by the atmospheric model) year-round by an additional $3 \mathrm{~K}$ (see Fig. 6b). Thereafter, climatological SST forcing was applied for another 200 model years. Figure 6 shows the SAT, 800 mbar geopotential height and surface winds response to the GIN Sea SST perturbation. Anomalous high pressure forms in the eastern GIN Sea in response to the lower-thannormal SST. Low pressure anomalies develop over Greenland and east of the Hudson Bay, in good qualitative agreement with the diagnosed atmospheric circulation changes during a weakened GSOC state (Fig. 3c). This experiment supports the notion of a strong atmospheric teleconnection between the GIN Sea and the western North Atlantic that was proposed in Sect. 4.2 to explain the connection between GSOC and AMOC.

To demonstrate the effects of subsurface ocean warming on the recovery of the GSOC we designed a fully coupled experiment in which subsurface temperatures between $200-5500 \mathrm{~m}$ were climatologically prescribed in the GIN Sea during a weak

Orbital modulation of AMOC variability

T. Friedrich et al.

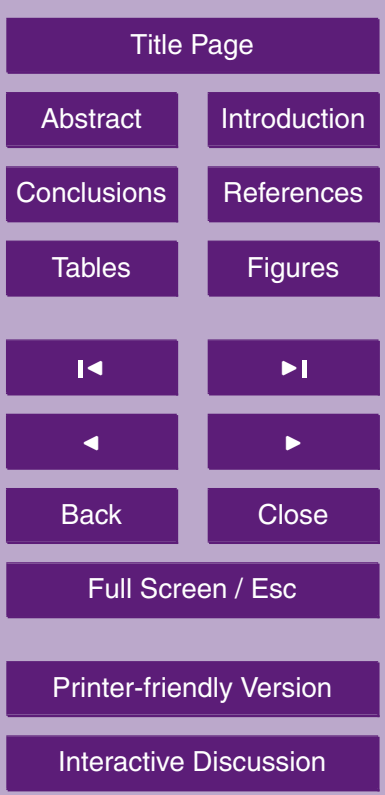


GSOC phase. In this sensitivity experiment we repeated the OBL22.4 run for 500 years starting in a weak GSOC/AMOC state (year 2801, see Fig. 2c, g). Here, the first 50 model years were used to create a subsurface temperature climatology for the GIN Sea. This climatology was then prescribed for the GIN Sea for the subsequent 200 5 years for water depths between 200-5500 m. The model was integrated for another 300 years with prognostic temperatures everywhere, including the GIN Sea. The resulting GSOC and subsurface temperatures (averaged over the GIN Sea) can be seen in Fig. 7a, b. Shortly after model year 2900 GSOC in the original OBL22.4 (Fig. 7a and black line in c) experiment recovers abruptly. However, in the sensitivity run (Fig. 7b

10 and blue line in c) prescribed subsurface temperatures impede further warming of sub thermocline waters in the GIN Sea. Accordingly stratification is not eroded and GSOC stays in a weak state. After returning to fully prognostic temperatures in the GIN Sea in model year $3001 \mathrm{GSOC}$ increases by about $0.5 \mathrm{~Sv}$ and fully recovers in a thermohaline flush around model year 3100 . This sensitivity experiment demonstrated that subsur15 face warming in the GIN Sea, that is reminiscent of deep-decoupling dynamics, plays a key role in the recovery of the AMOC.

\subsection{Global Impacts of millennial-scale AMOC variability}

In our model simulations, the consequences of an abrupt AMOC reduction of about $30 \%$ (in the case of the OBL22.4 and OBL22.1 run) can be detected on a global scale.

20 Figure 8 shows the simulated composite differences in SAT and precipitation between a strong (AMOC >27 Sv) and a weak (AMOC <21 Sv) AMOC state for the OBL22.1 experiment. The main response pattern is the so-called bi-polar seesaw (Broecker, 1998) with large-scale warming in the Northern Hemisphere and cooling in the Southern Hemisphere. This pattern is associated with a northward displacement of the In25 tertropical Convergence Zone for strong overturning in the North Atlantic (Fig. 8). Over Greenland, millennial-scale SAT anomalies attain magnitudes of up to $7 \mathrm{~K}$ and are closely linked with \pm 6 Sv AMOC variations (Fig. 9). Simulated millennial-scale surface air temperature variations as well as their corresponding hydrological effects resem-

Orbital modulation of AMOC variability

T. Friedrich et al.

Title Page

Abstract Introduction

Conclusions References

Tables Figures

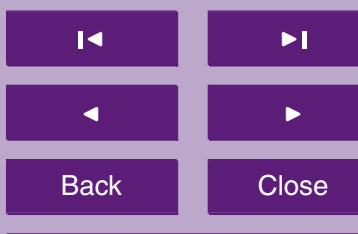

Full Screen / Esc

Printer-friendly Version

Interactive Discussion 
ble the spatio-temporal characteristics of the well-known DO oscillations (Dansgaard et al., 1982; Stott et al., 2002; EPICA Community Members, 2006; Tjallingii et al., 2008). Whereas the simulated rainfall anomalies are relatively small (5-10\%) over the equatorial oceans, their relative magnitudes over the Sahara and the Sahel are very 5 considerable $(\sim 40 \%)$.

The precipitation and temperature changes induce variations in terrestrial vegetation. Periods characterized by a weak AMOC are associated with a reduced terrestrial carbon stock (Fig. 10a, b). On the other hand, the relatively cold conditions prevailing during weak AMOC periods lead to greater $\mathrm{CO}_{2}$ solubility and an increased storage of 10 carbon in the ocean. During a weak AMOC state, the decrease in terrestrial vegetation is not entirely balanced by increased $\mathrm{CO}_{2}$ solubility. Hence weak AMOC states are accompanied by an overall increase of atmospheric $\mathrm{CO}_{2}$ by about $10 \mathrm{ppm}$. A similar mechanism for externally forced millennial-scale $\mathrm{CO}_{2}$ variations was already proposed in Menviel et al. (2008a). However, it was already noted in Menviel et al. (2008a) that 15 the details of the terrestrial and marine carbon cycle response to AMOC variations may strongly depend on the climate background state. Under colder and drier glacial conditions, the terrestrial carbon response might be reduced significantly.

Paleo-data evidence (Kennett and Ingram, 1995) suggests that variations in anoxic conditions in the Santa Barbara and the California current region varied in unison with 20 the major DO events. In the OBL22.1 simulation millennial-scale oxygen content variations averaged over 250-350 m depth along the coasts of Baja California and Southern California are out-of-phase with the AMOC index (Fig. 10c), in accordance with Kennett and Ingram (1995) and the model results of Schmittner et al. (2007). Our results indicate that variations in trade winds and North Pacific westerly winds intensity 25 (Mikolajewicz et al., 1997) as well as large-scale reorganizations of the Pacific ocean circulation (not shown) and primary productivity (Schmittner et al., 2007) are the cause of millennial-scale variations in anoxic conditions in the northeastern Pacific. A more in-depth analysis of these changes will be conducted in a forthcoming study.
5, 2019-2051, 2009

Orbital modulation of AMOC variability

T. Friedrich et al.

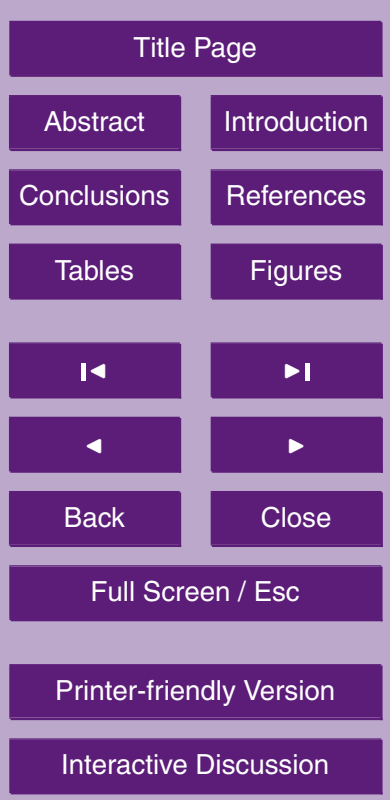

Interactive Discussion

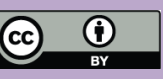




\subsection{Effects of different bathymetry}

The driving mechanism for millennial-scale AMOC variability in our model heavily relies on the emergence of freshwater flushes from the Hudson Bay into the Labrador Sea and the subsequent reduction of Labrador Sea convection. However, during the last 5 glacial period Hudson Bay was covered by the Laurentide ice sheet. Thus we expect that LGM boundary conditions would prevent the generation of millennial-scale AMOC variability in OBL22.1. To demonstrate this effect we repeated the OBL22.1 run using an estimate of the LGM-ocean bathymetry (LGM22.1 run, Table 1) (Roche et al., 2007). In addition, the river runoff mask as well as the land-sea fraction mask were adjusted to LGM values. Atmospheric topographic forcing was kept at present-day values.

Figure 11 clearly shows that LGM-bathymetry suppresses millennial-scale AMOC variability. Even though the GSOC index exhibits some sawtooth behavior with multiple, rapid increases of $\sim 1.5 \mathrm{~Sv}$ followed by gradual reductions, no significant centennial-tomillennial scale variability can be seen for the AMOC. A more detailed analysis (not 15 shown) revealed that the atmospheric response to GSOC reductions is similar to the one shown in Fig. 3c with anomalous high-pressure over the GIN Sea sinking region and lower pressure between the southern tip of Greenland and Iceland. However, in the absence of a "freshwater pool" such as the Hudson Bay this atmospheric teleconnection is not able to trigger changes of Labrador Sea convection and hence suppresses AMOC variability.

\section{Conclusions}

This paper explored the mechanism responsible for the generation of centennial-tomillennial scale AMOC oscillations and their relation to obliquity in the LOVECLIM climate model. Our findings show that these nonlinear and stochastically excited oscillations disappear under glacial boundary conditions (namely glacial bathymetry). Similar to the findings presented by Schulz et al. (2007) we conclude that the mechanism iden-

5, 2019-2051, 2009

Orbital modulation of AMOC variability

T. Friedrich et al.

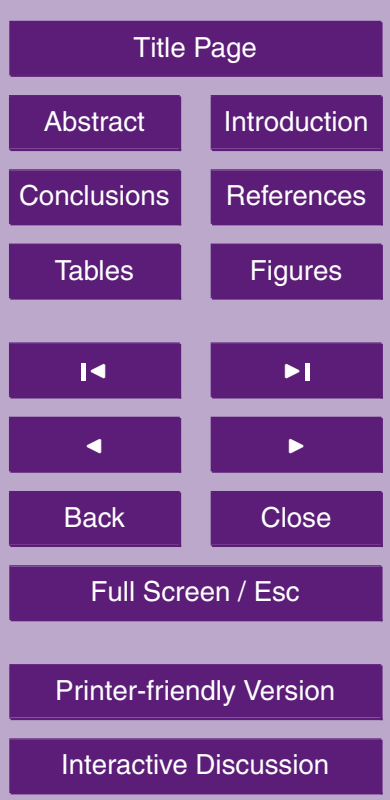

Interactive Discussion

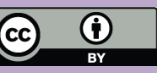


tified for our model solution must be fundamentally different from the one that triggered real Dansgaard-Oeschger events during the last glacial period.

We also conducted several experiments with boundary conditions intermediate between pre-industrial and LGM as described in Rial and Yang (2007) and Rial and Saha 5 (2008). We were able to reproduce their modeling results qualitatively (not shown) using flat ice-sheet boundary conditions and different orbital configurations. Hence, we assume that the physical mechanism underlying the millennial-scale DO-like oscillation in Rial and Yang (2007) and Rial and Saha (2008) is the same as the one diagnosed in our study. However, our closed Hudson Bay experiments clearly demonstrate that 10 the mechanism that is powering the simulated millennial-scale oscillations in ECBiltCLIO/LOVECLIM has to be distinct from the one that triggers Dansgaard-Oeschger oscillations in reality - in contrast to the conclusions of Rial and Yang (2007) and Rial and Saha (2008).

The oscillations identified in ECBilt-CLIO described in Schulz et al. (2007) and 15 Jongma et al. (2007) share several important features with the millennial-scale oscillations in our study. Among them are the atmospheric anomaly pattern, the magnitude of the AMOC oscillations and the important role of salinity. However, there appear to be key differences in the model simulations, such as the lack of a convection breakdown in the GIN Sea in Schulz et al. (2007). Furthermore their advective horizontal recovery 20 mechanism for Labrador Sea convection contrasts our deep-decoupling resumption mechanism for the GIN Sea.

While the oscillatory model solution may depend strongly on regional features, such as the existence or absence of the Hudson Bay, the overall simulated teleconnection patterns bear quite some similarity to those observed for DO events. In accordance with numerous paleo-data, we found that the $\pm 6 \mathrm{~Sv}$ variations of the AMOC are accompanied by the bipolar seesaw pattern in surface air temperature and large-scale changes of tropical hydroclimate, with the northern tropics drying and the southern tropics becoming wetter for weak overturning in the North Atlantic. Corresponding precipitation changes affect the overall terrestrial carbon stock and hence atmospheric
5, 2019-2051, 2009

Orbital modulation of AMOC variability

T. Friedrich et al.

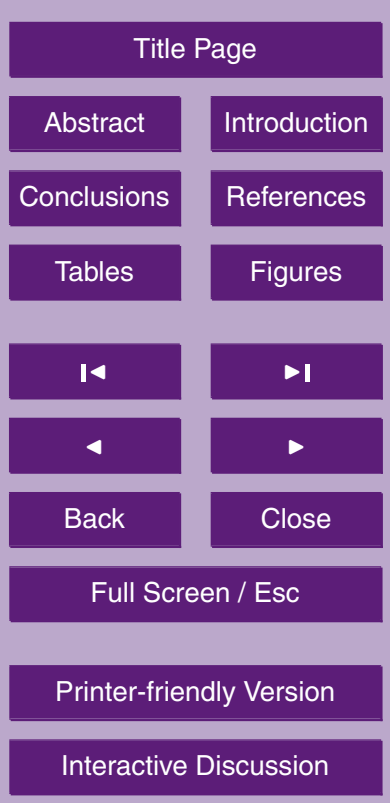

Interactive Discussion

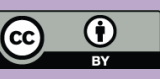


$\mathrm{CO}_{2} \cdot \mathrm{A}+6 \mathrm{~Sv}(-6 \mathrm{~Sv})$ change of the AMOC generates atmospheric $\mathrm{CO}_{2}$ anomalies of of $-5 \mathrm{ppm}(+5 \mathrm{ppm})$. Future higher resolution ice-core data from Antarctica might help to confirm whether $\mathrm{DO}$ events were in fact accompanied by significant $\mathrm{CO}_{2}$ variations in the direction predicted here.

$5 \quad$ Our coupled modeling results lend further support to the concept of deep-decoupling oscillations in 3-dimensional coupled climate models. Identified previously in simplified climate models (Ganopolski and Rahmstorf, 2002; Timmermann et al., 2003) or idealized OGCMs (Winton and Sarachik, 1993), our more realistic model configuration demonstrated the possibility for the emergence of deep-decoupling phases in the GIN

10 Sea. By preventing deep-ocean warming in the GIN Sea we were able to suppress the rapid recovery of the AMOC. The GIN Sea appears to be a key region for the amplification of noise-induced variability of the overturning circulation.

Summarizing, different mechanisms have been postulated to explain the observed DO cycles using models of different complexity. Mechanisms include stochastic and 15 periodic excitations of stable and metastable states (Ganopolski et al., 1998). However, without careful considerations of the orbital influences on internally generated millennial-scale AMOC variability, a convincing assessment of the mechanisms for observed DO variability remains elusive.

Acknowledgements. T. Friedrich and L. Menviel are supported by the National Science Foun20 dation under grant number ATM-0712690. A. Timmermann and O. Timm are supported by the Japan Agency for Marine-Earth Science and Technology (JAMSTEC) through its sponsorship of the International Pacific Research Center. D. M. Roche is supported by NWO under the RAPID project ORMEN.

\section{References}

25 Aeberhardt, M., Blatter, M., and Stocker, T. F.: Variability on the century timescale and regime changes in a stochastically forced zonally averaged ocean-atmosphere model, Geophys. Rev. Lett., 27, 1303-1306, 2000. 2021

Orbital modulation of AMOC variability

T. Friedrich et al.
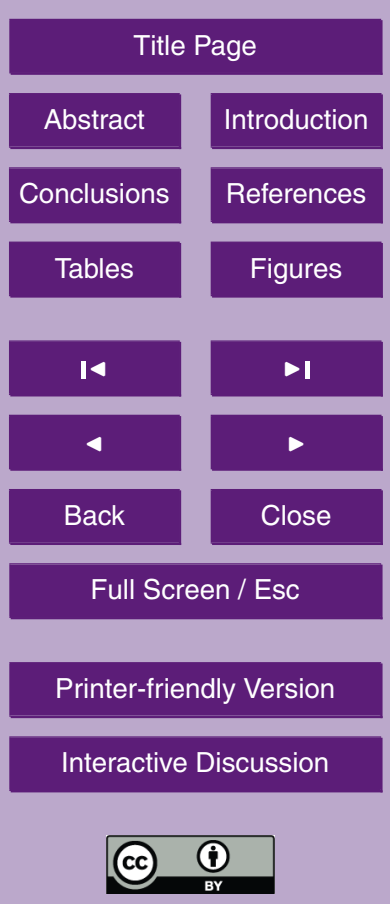
Alley, R. B., Anandakrishnan, S., and Jung, P.: Stochastic Resonance in the North Atlantic, Paleoceanography, 16, 190-198, 2001. 2020, 2021, 2022

Broecker, W. S.: Paleocean circulation during the last deglaciation: A bipolar seesaw?, Paleoceanogr., 13, 119-121, 1998. 2031

5 Broecker, W. S., Bond, G., and Klas, M.: A salt oscillator in the glacial Atlantic? 1. The concept, Paleoceanography, 5, 469-477, 1990. 2021

Brovkin, V., Ganopolski, A., and Svirezhev, Y.: A continuous climate-vegetation classification for use in climate-biosphere studies, Ecol Model, 101, 251-261, 1997. 2023

Dansgaard, W.: Evidence for general instability of past climate from a $250 \mathrm{kyr}$ ice-core records, $10 \quad$ Nature, 364, 218-220, 1993. 2020

Dansgaard, W., .Clausen, H., Gundestrup, N., Hammer, C. U., Johnsen, S. F., Kristinsdottir, P. M., and Reeh, N.: A new Greenland deep ice core, Science, 218, 1273-1277, 1982. 2020, 2032

Deser, C., Magnusdottir, G., Saravanan, R., and Phillips, A.: The effects of North Atlantic 15 SST and sea-ice anomalies on the winter circulation in CCM3, Part II: Direct and indirect components of the response, J. Climate, 17, 877-889, 2004. 2027

Driesschaert, E.: Climate change over the next millennia using LOVECLIM, a new Earth system model including the polar ice sheets, Ph.D. thesis, Universite Catholique de Louvain, Louvain-la-Neuve, Belgium, http://www.astr.ucl.ac.beusers/driess/thesis_web.pdf, 2005. 2023

EPICA Community Members: One-to-one coupling of glacial climate variability in Greenland and Antarctica, Nature, 195-198, 2006. 2032

Ganopolski, A. and Rahmstorf, S.: Abrupt glacial climate change due to stochastic resonance, Phys. Rev. Lett., 88, 038501-1-038501-4, 2002. 2021, 2035

Ganopolski, A., Rahmstorf, S., Petoukhov, V., and Claussen, M.: Simulation of modern and glacial climates with a coupled global model of intermediate complexity, Nature, 391, 351356, 1998. 2020, 2021, 2025, 2035

Goosse, H., Deleersnijder, E., Fichefet, T., and England, M.: Sensitivity of a global coupled ocean-sea ice model to the parameterization of vertical mixing, J. Geophys. Res., 104(C6), 13681-13695, 1999. 2023

GRIP Project Members: Climate instability during the last interglacial period recorded in the GRIP ice core, Nature, 364, 203-207, 1993. 2020

Johnsen, S. J., Clausen, H. B., Dansgaard, W., Gundestrup, K. F. N., Hammer, C. U., Iversen,

Orbital modulation of AMOC variability

T. Friedrich et al.

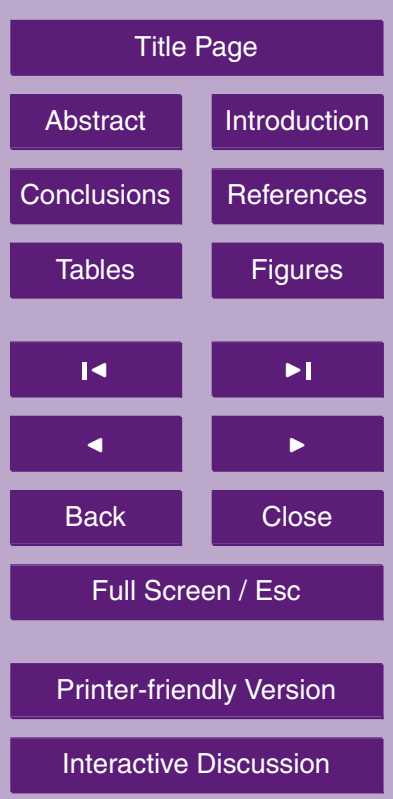


P., Jouzel, J., Stauffer, B., and steffensen, J. P.: Irregular glacial interstadials recorded in a new Greenland ice core, Nature, 359, 311-313, 1992. 2020

Jongma, J. I., Prange, M., Renssen, H., and Schulz, M.: Amplification of Holocene multicentennial climate forcing by mode transitions in North Atlantic overturning circulation, Geophys.

$5 \quad$ Res. Lett., 34, L15706, doi:10.1029/2007GL030642, 2007. 2021, 2022, 2026, 2034

Kennett, J. and Ingram, B.: A 20,000 year record of ocean circulation and climate change in the Santa Barbara basin, Nature, 377, 510-514, 1995. 2032

Levitus, S.: Climatological Atlas of the World Ocean, Tech. rep., NOAA Prof. Paper 13, 173pp, 1994. 2027

10 Liu, Z., Bliesner, B.-L. O., F. He, E. B., R. Tomas, P. C., Carlson, A., J. Lynch-Stieglitz, W. C., Brook, E., Erickson, D., Jacob, R., Kutzbach, J., and Cheng, J.: Transient Simulation of the Last Deglaciation with a new Mechanism for Bølling-Allerød Warming, Science, in press, 2009. 2021

Menviel, L., Timmermann, A., Mouchet, A., and Timm, O.: Meridional reogranization of 15 marine and terrestrial productivity during Heinrich events, Paleoceanogr., 23, PA1203, doi:10.1029/2007PA001445, 2008a. 2024, 2025, 2032

Menviel, L., Timmermann, A., Mouchet, A., and Timm, O.: Climate and marine carbon cycle response to changes in the strength of the southern hemispheric westerlies, Paleoceanogr., 23, PA4201, doi:10.1029/2008PA001604, 2008b. 2024

20 Mikolajewicz, U., Crowley, J., Schiller, J., and Voss, R.: Modeling teleconnections between the North Atlantic and North Pacific during the Younger Dryas, Nature, 387, 384-387, 1997. 2032

Mouchet, A. and Francois, L. M.: Sensitivity of a global ocean carbon cycle model to the circulation and the fate of organic matter: Preliminary results, Phys. Chem. Earth, 511-516, 1996. 2024

NGRIP Project Members: High-resolution record of Northern Hemisphere climate extending into the last interglacial period, Nature, 431, 147-151, 2004. 2020

Oeschger, H., Beer, J., Siegenthaler, U., Stauffer, B., Dansgaard, W., and Langway, C.: Late glacial climate from ice cores, Geophysical Monograph, 29, 299-306, 1984. 2020

30 Paul, A. and Schulz, M.: Holocene climate variability on centennial-to-millennial time scales: 2. Internal feedbacks and external forcings as possible causes, Climate Development and History of the North Atlantic Realm, 55-73, 2002. 2021

Pikovsky, A. S. and Kurths, J.: Coherence resonance in a noise-driven excitable system, Phys-

Orbital modulation of AMOC variability

T. Friedrich et al.
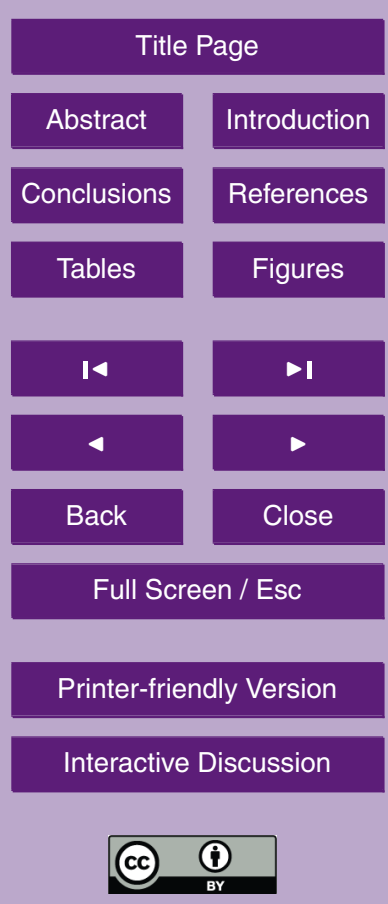
ical Review Letters, 78, 775-778, 1997. 2022

Rial, J. and Saha, R.: Stochastic Resonance, Frequency Modulation and the Mechanisms of Abrupt Climate Change in the Arctic (Extended Abstract), 94-97, the First International Symposium on Arctic Research: Drastic Change Under Global, 2008. 2021, 2022, 2034

5 Rial, J. A. and Yang, M.: Is the frequency of abrupt climate change modulated by the orbital insolation?, 67-174, Geophysical Monograph Series 173, Ocean Circulation, Mechanisms and Impacts, edited by: Hamming, S., 2007. 2021, 2022, 2034

Roche, D. M., Dokken, T. M., Goosse, H., Renssen, H., and Weber, S. L.: Climate of the Last Glacial Maximum: sensitivity studies and model-data comparison with the LOVECLIM coupled model, Clim. Past, 3, 205-224, 2007,

http://www.clim-past.net/3/205/2007/. 2025, 2033

Schmittner, A., Galbraith, E., Hostetler, S., Pedersen, T., and Zhang, R.: Large fluctuations of dissolved oxygen in the Indian and Pacific oceans during Dansgaard-Oeschger oscillations caused by variations of North Atlantic Deep Water subduction, Paleoceanography, 22,

15 PA3207, doi:10.1029/2006PA001 384, 2007. 2032

Schulz, M., Paul, A., and Timmermann, A.: Relaxation oscillators in concert: A framework for climate change at millennial timescales during the late Pleistocene, Geophys. Res. Lett., 29, 2193, doi:10.1029/2002GL016144, 2002. 2026

Schulz, M., Prange, M., and Klocker, A.: Low-frequency oscillations of the Atlantic Ocean meridional overturning circulation in a coupled climate model, Clim. Past, 3, 97-107, 2007, http://www.clim-past.net/3/97/2007/. 2021, 2022, 2025, 2026, 2033, 2034

Stommel, H.: Thermohaline convection with two stable regimes of flow, Tellus, 13, 224-230, 1961. 2021

Stott, L., Poulsen, C., Lund, S., and Thuell, R.: Super ENSO and Global Climate Oscillations at Millenial Time Scales, Science, 297, 222-226, 2002. 2032

Timmermann, A. and Goosse, H.: Is the wind-stress forcing essential for the meridional overturning circulation?, Geophys. Res. Lett., 31, L04303, doi:10.1029/2003GL018777, 2004. 2021

Timmermann, A., Gildor, H., Schulz, M., and Tziperman, E.: Coherent resonant millennial-scale 30 climate oscillations triggered by massive meltwater pulses, J. Climate, 16(15), 2569-2585, 2003. 2020, 2022, 2026, 2035

Tjallingii, R., Claussen, M., Stuut, J.-B., Fohlmeister, J., Jahn, A., Bickert, T., Lamy, F., and Röhl, U.: Coherent high- and low-latitude forcing of the Northwest African humidity, Nature

Orbital modulation of AMOC variability

T. Friedrich et al.

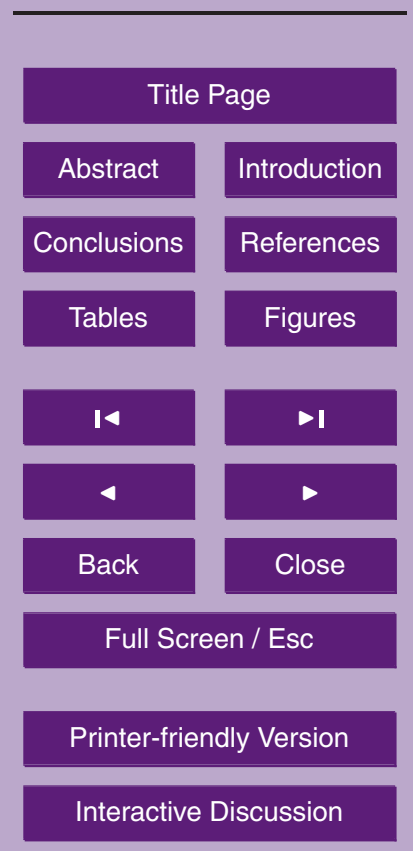

Interactive Discussion

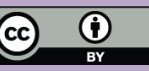


Geoscience, 289, 670-675, 2008. 2032

Winton, M.: Deep decoupling oscillation of the oceanic thermohaline circulation, Ice in the Climate System, 12, 417-432, 1993. 2021

Winton, M. and Sarachik, E. S.: Thermohaline oscillations induced by strong steady salinity 5 forcing of ocean general circulation models, J. Phys. Oceanogr., 23, 1389-1410, 1993. 2021, 2035
5, 2019-2051, 2009

Orbital modulation of AMOC variability

T. Friedrich et al.

\begin{tabular}{|c|c|}
\hline \multicolumn{2}{|c|}{ Title Page } \\
\hline Abstract & Introduction \\
\hline Conclusions & References \\
\hline Tables & Figures \\
\hline I4 & \\
\hline 4 & $\checkmark$ \\
\hline Back & Close \\
\hline Full Screen / Esc \\
\hline Printer-friendly Version
\end{tabular}




\section{Orbital modulation of} AMOC variability

T. Friedrich et al.

Table 1. Abbreviation, obliquity and bathymetry for different model runs. For all runs eccentricity, precession, sea level, land topography, land albedo and atmospheric $\mathrm{CO}_{2}$ concentration were kept at pre-industrial values.

\begin{tabular}{ccc}
\hline Model run & Obliquity & Bathymetry \\
\hline CTR & $23.446^{\circ}$ & present-day \\
OBL22.8 & $22.8^{\circ}$ & present-day \\
OBL22.4 & $22.4^{\circ}$ & present-day \\
OBL22.1 & $22.1^{\circ}$ & present-day \\
LGM 22.1 & $22.1^{\circ}$ & LGM \\
\hline
\end{tabular}

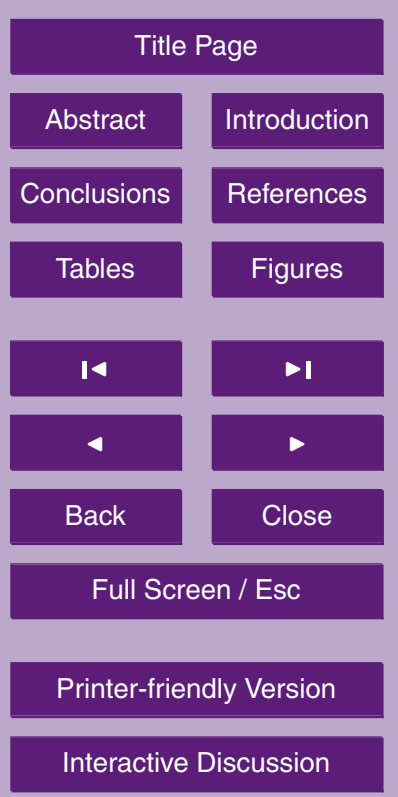




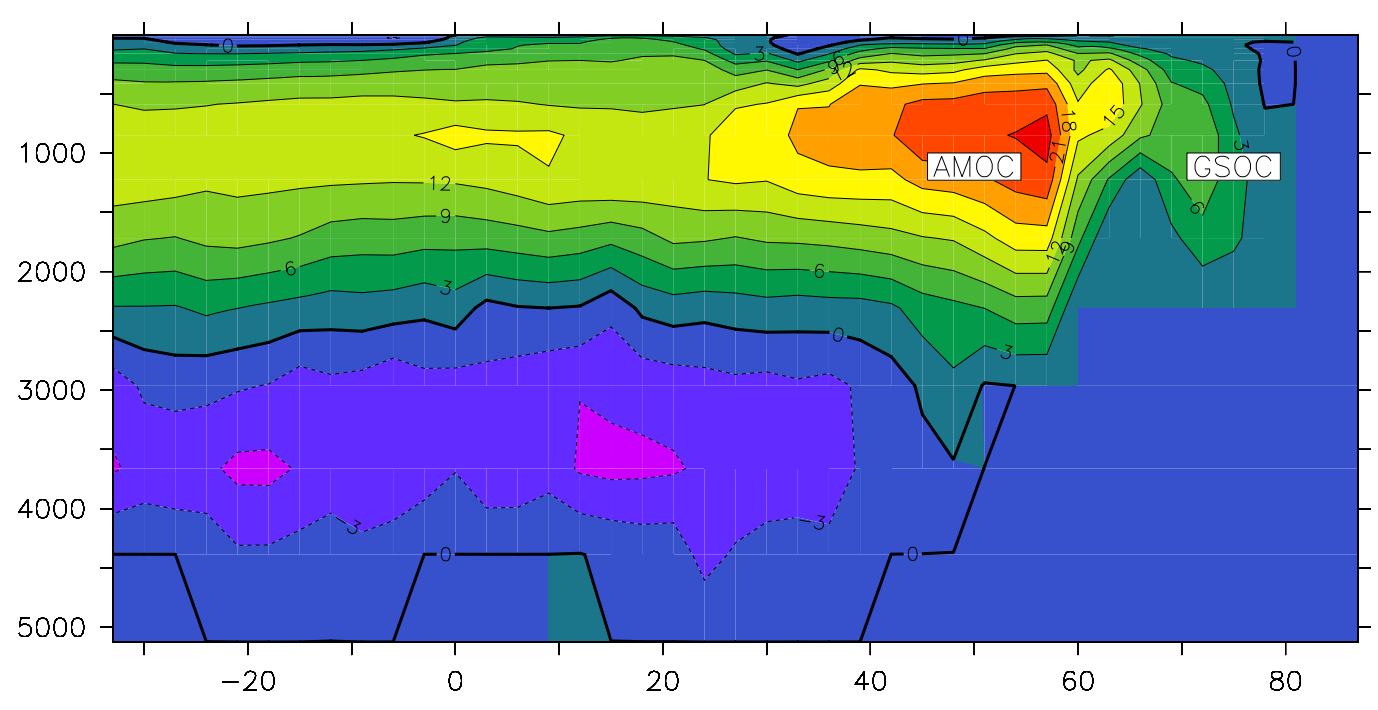

Fig. 1. Mean Atlantic Meridional Overturning Circulation for the control simulation in Sv. The two cells that are referred to in the text - GIN Sea overturning circulation (GSOC) and maximum of Atlantic overturning circulation (AMOC) - are indicated by the labels.

\section{Orbital modulation of} AMOC variability

T. Friedrich et al.

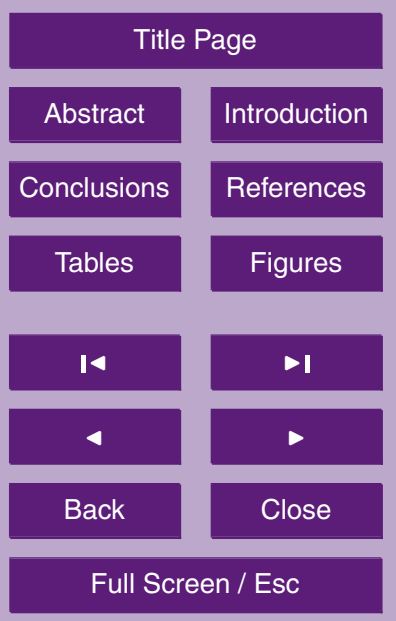

Printer-friendly Version

Interactive Discussion 

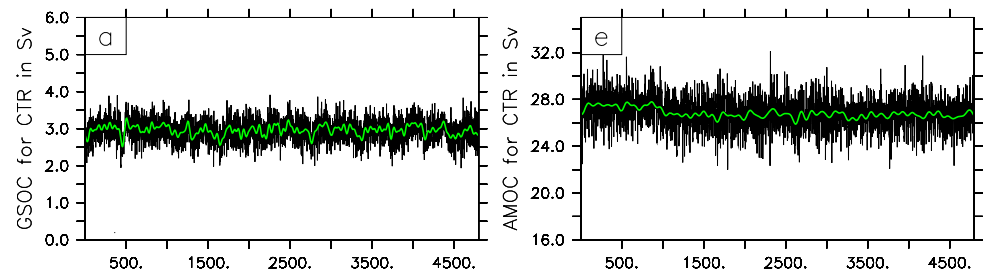

5, 2019-2051, 2009
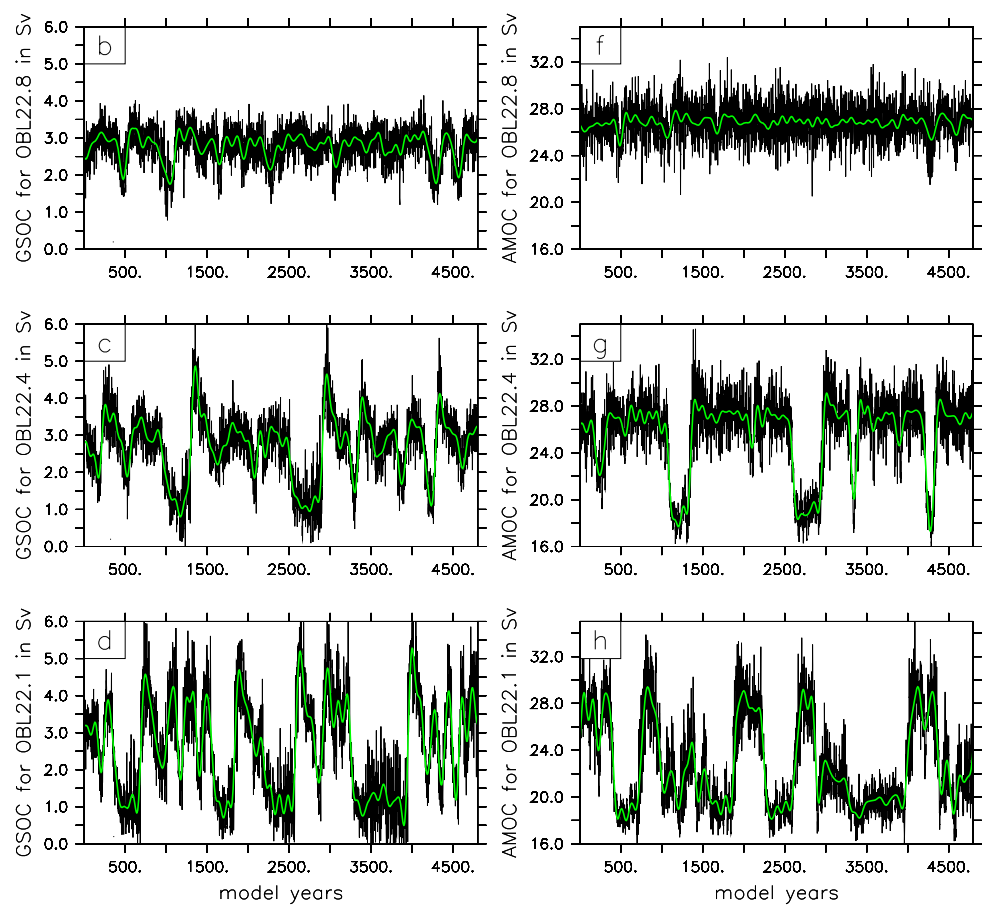

Fig. 2. (a-d) GIN Sea overturning circulation (GSOC) and maximum of Atlantic overturning circulation (AMOC) (e-h) in Sv for indicated model simulations. A low pass filter of 50 years was applied for green lines.

Orbital modulation of AMOC variability

T. Friedrich et al.

Title Page

\begin{tabular}{|c|c|}
\hline Abstract & Introduction \\
\hline Conclusions & References \\
\hline Tables & Figures \\
\hline I4 & \multicolumn{1}{|c|}{$\mid$} \\
\hline 4 & \\
\hline Back & Close \\
\hline Full Screen / Esc \\
\hline Printer-friendly Version \\
\hline Interactive Discussion
\end{tabular}



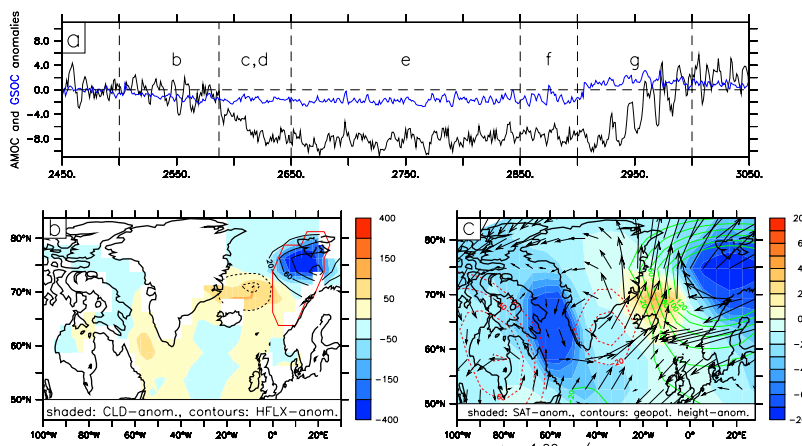

Orbital modulation of AMOC variability

T. Friedrich et al.
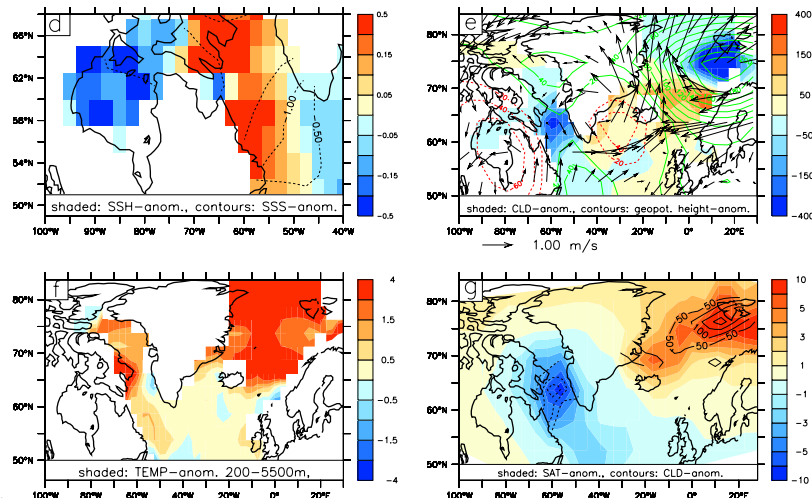

Fig. 3. (a) Anomalies of AMOC (black) and GSOC (blue) in Sv for the OBL22.4 run for the timeframe 2450-3050 (see also Fig. 2c,g). Dashed vertical lines denote averaging intervals for panels b-g. (b) Anomalies in convective layer depth (CLD) in $\mathrm{m}$ (shaded) and surface heat flux (HFLX) in $\mathrm{W} / \mathrm{m}^{2}$ (contours). A positive HFLX anomaly is associated with a lower-than-normal heat loss of the surface ocean to the atmosphere. The red line indicates the mean GIN Sea sinking region in the model. (c) Anomalies of surface air temperature (SAT) in K (shaded), 800 mbar geopotential height in $\mathrm{m}^{2} / \mathrm{s}^{2}$ (contours) and wind speed (arrows). (d) Anomalies of sea surface height in $\mathrm{m}$ (shaded) and sea surface salinity in psu (contours). (e) Anomalies in CLD in m (shaded), $800 \mathrm{mbar}$ geopotential height in $\mathrm{m}^{2} / \mathrm{s}^{2}$ (contours) and wind speed (arrows). (f) Anomalies of oceanic temperature in K averaged over 200-5500 m. (g) SAT anomalies in K (shaded) and CLD anomalies in $\mathrm{m}$ (contours). All anomalies in panels $\mathrm{b}-\mathrm{g}$ are averaged over the interval indicated by the respective letter in panel (a).

Title Page

\begin{tabular}{|c|c|}
\hline \multicolumn{2}{|c|}{ Title Page } \\
\hline Abstract & Introduction \\
\hline Conclusions & References \\
\hline Tables & Figures \\
\hline I4 & \multicolumn{1}{|c|}{} \\
\hline 4 & $\checkmark$ \\
\hline Back & Close \\
\hline Full Screen / Esc \\
\hline Printer-friendly Version \\
\hline Interactive Discussion
\end{tabular}

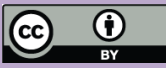



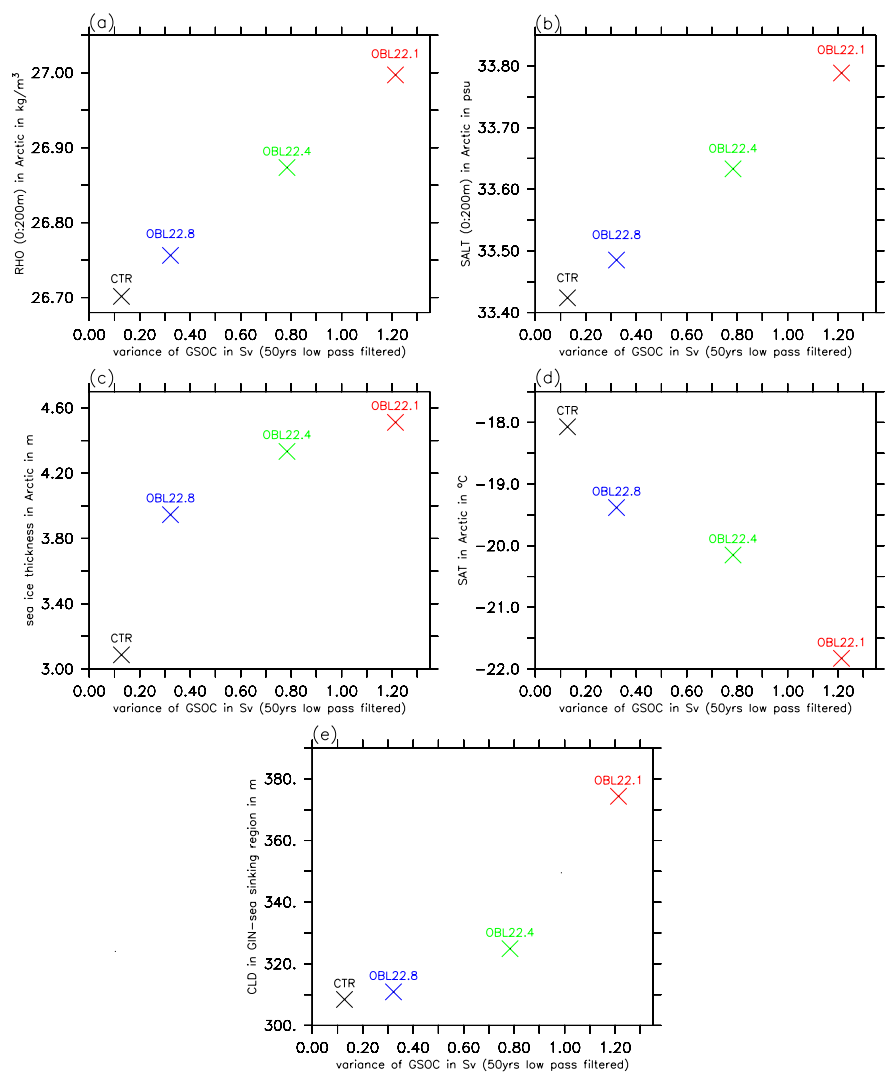

Fig. 4. Annual mean variables (upper ocean density, upper ocean salinity, sea-ice thickness, surface air-temperature convective layer depth) averaged over $66^{\circ} \mathrm{N}$ to $90^{\circ} \mathrm{N}$ for a strong GSOC state versus variance of 50 years low pass filtered GSOC for different model simulations (CTR, OBL22.8, OBL22.4, OBL22.1), representing different orbital configurations. An obliquity value of $23.446^{\circ}$ was used for the control run (CTR).

Orbital modulation of AMOC variability

T. Friedrich et al.

Title Page

\begin{tabular}{c|c}
\hline Abstract & Introduction \\
\hline Conclusions & References \\
\hline Tables & Figures \\
\hline I4 & $\checkmark \mathbf{I}$ \\
\hline 4 & $\triangleright$ \\
\hline Back & Close \\
\hline Full Screen / Esc
\end{tabular}

Printer-friendly Version

Interactive Discussion 


\section{Orbital modulation of} AMOC variability

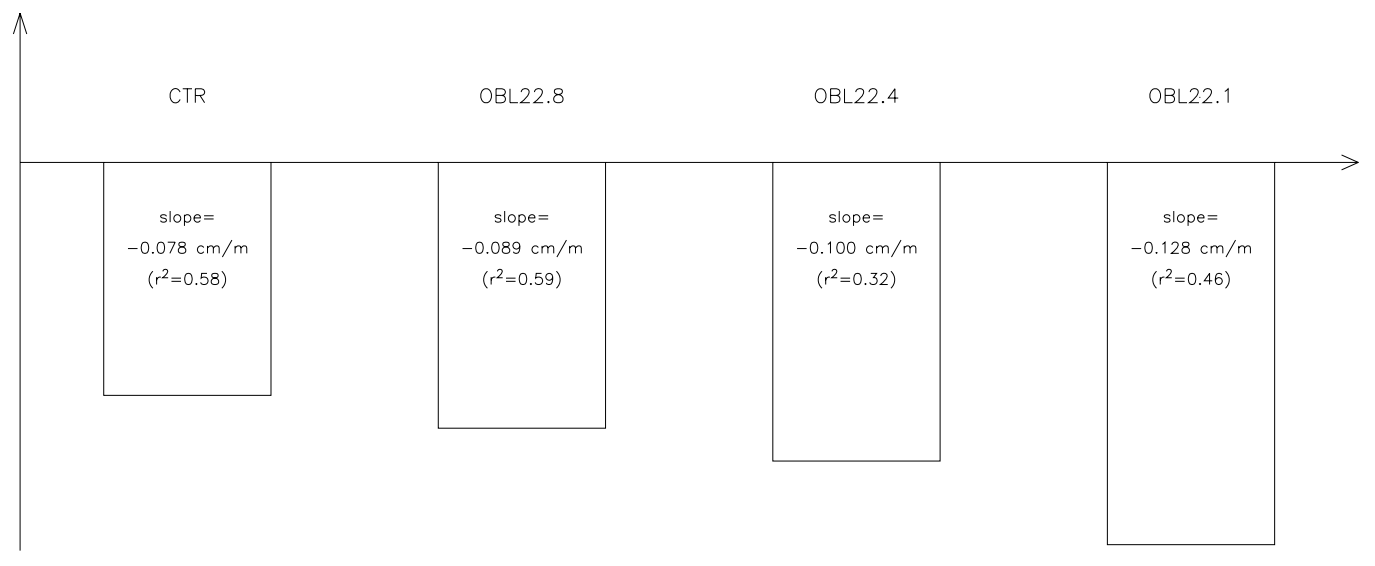

T. Friedrich et al.

Fig. 5. Linear regression coefficients $[\mathrm{cm} / \mathrm{m}$ ] of sea ice thickness anomaly and CLD anomaly during a strong GSOC state in the GIN Sea sinking region (red line in Fig. 3b) for different obliquity values. An obliquity value of $23.446^{\circ}$ was used for the control run (CTR).

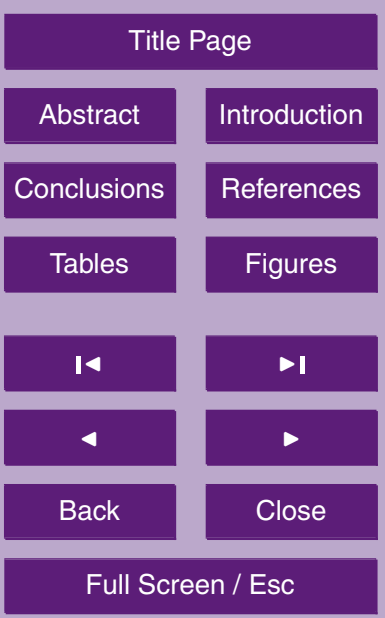

Printer-friendly Version

Interactive Discussion

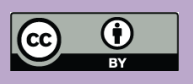



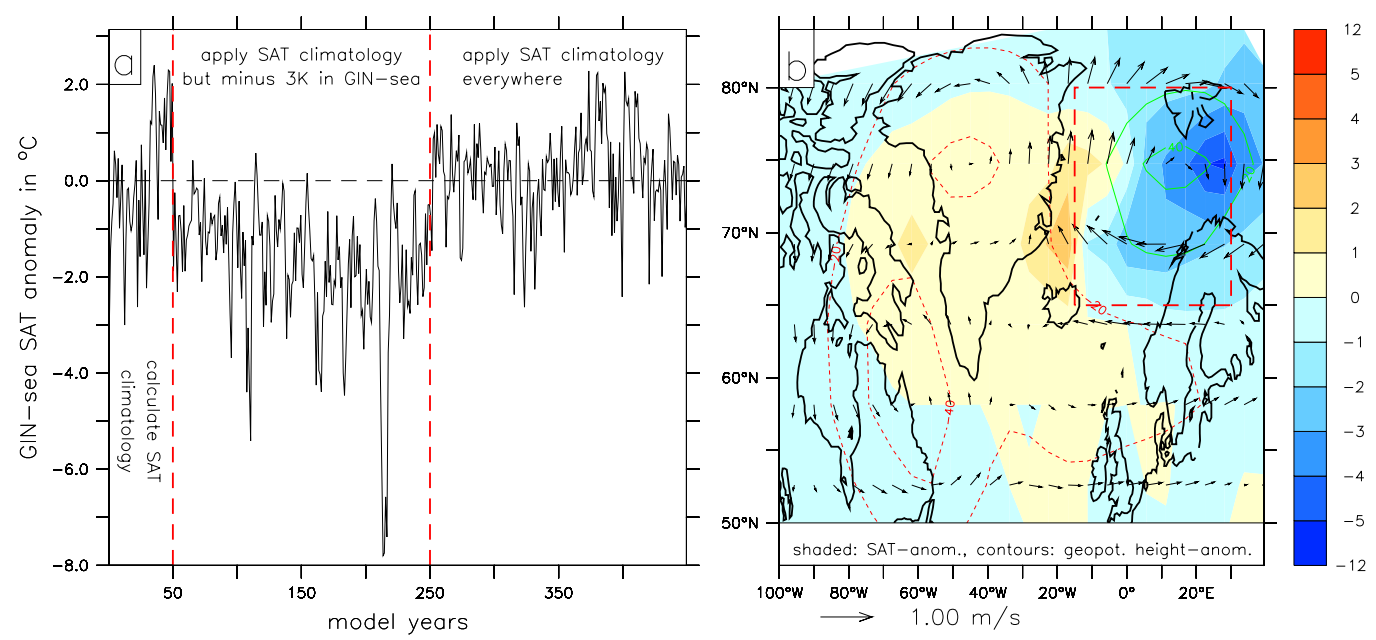

\section{Orbital modulation of} AMOC variability

T. Friedrich et al.

Fig. 6. (a) GIN Sea SAT anomaly (averaged over $15^{\circ} \mathrm{W}$ to $30^{\circ} \mathrm{E}$ and $65^{\circ} \mathrm{N}$ to $80^{\circ} \mathrm{N}$ ) with respect to the model years 1 to 50 of the sensitivity experiment. The red lines separate the three stages of the experiment. (b) Anomalies in SAT in K (shaded), $800 \mathrm{mbar}$ geopotential height in $\mathrm{m}^{2} / \mathrm{s}^{2}$ (contours) and wind speed (arrows) with respect to the model years 1 to 50 of the sensitivity experiment. The red rectangular indicates the region where the SST perturbation is applied to the GIN Sea atmosphere.

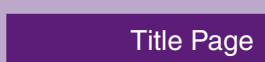

Abstract Introduction

Conclusions References

Tables

Figures

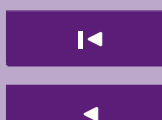

4

Back

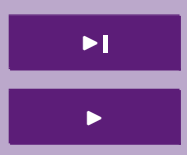

Close

Full Screen / Esc

Printer-friendly Version

Interactive Discussion 


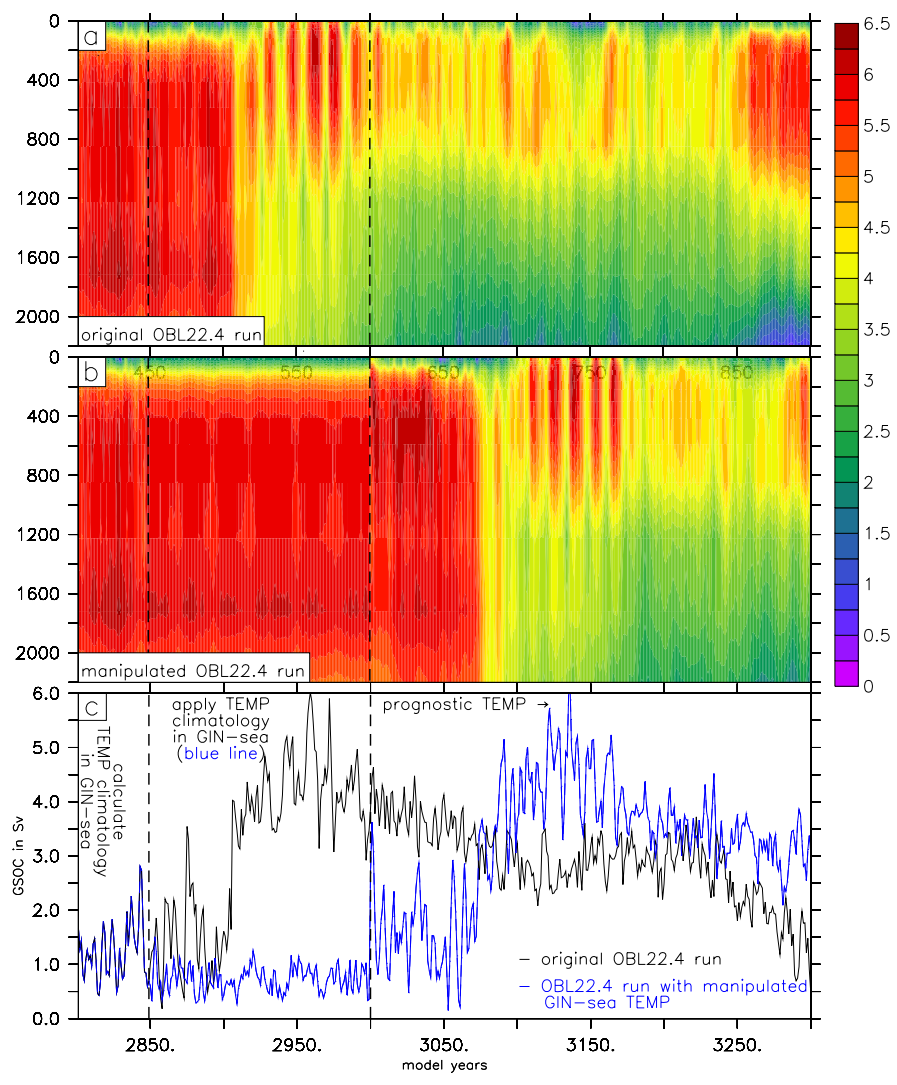

Fig. 7. (a, b) Hovmoeller diagrams of temperature averaged over GIN Sea in ${ }^{\circ} \mathrm{C}$ for original OBL22.4 run (a) and (b) a restart of OBL22.4 run in which a subsurface temperature "climatology" in the GIN Sea was generated from the years 2801 to 2850 and prescribed for years 2851 to 3000 . Subsequently the model were run another 300 years with prognostic temperatures in the GIN Sea. (c) GSOC for original (black line) and manipulated (blue line) OBL22.4 run in Sv for timeframe 2801-3300.
5, 2019-2051, 2009

Orbital modulation of AMOC variability

T. Friedrich et al.

\begin{tabular}{|c|c|}
\hline \multicolumn{2}{|c|}{ Title Page } \\
\hline Abstract & Introduction \\
\hline Conclusions & References \\
\hline Tables & Figures \\
\hline I4 & \\
\hline 4 & $-\mathbf{I}$ \\
\hline Back & Close \\
\hline Full Screen / Esc
\end{tabular}

Printer-friendly Version

Interactive Discussion 


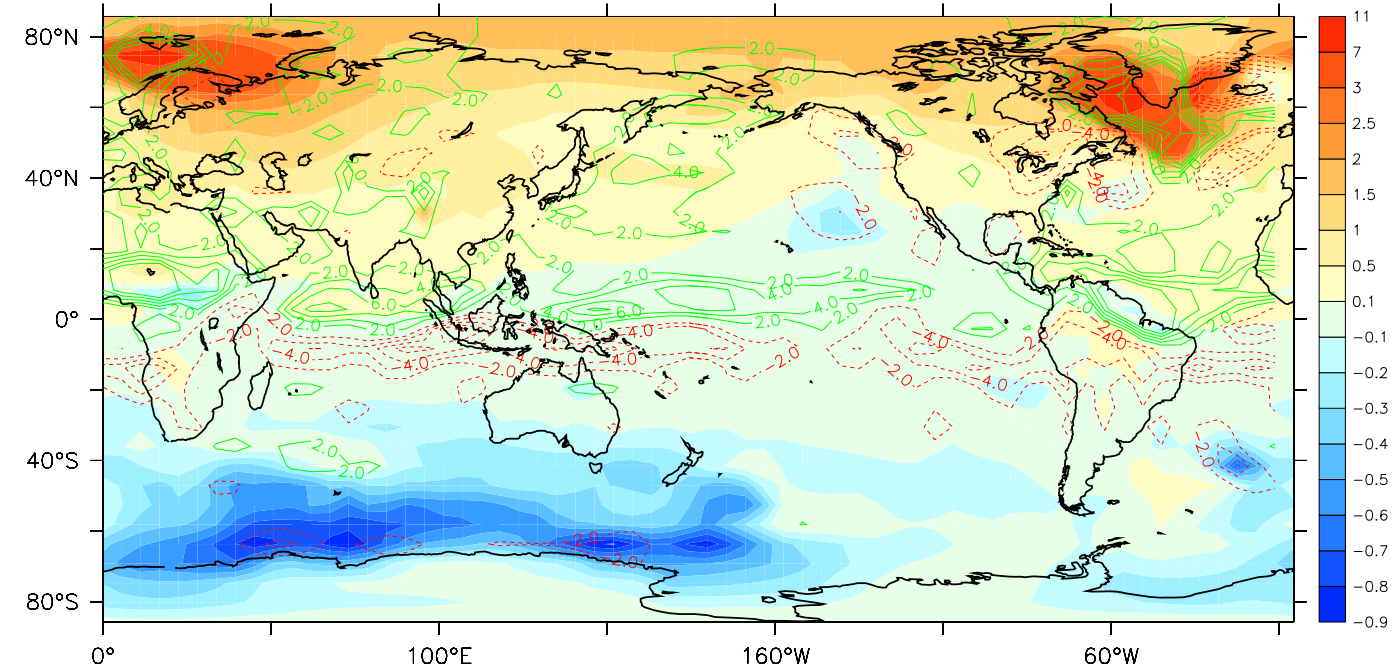

Fig. 8. SAT difference in $\mathrm{K}$ (shaded) and precipitation difference in $\mathrm{cm} / \mathrm{yr}$ (contours) between a strong and a weak AMOC state for the OBL22.1 run. A weak/strong state is defined by an AMOC $<21 \mathrm{~Sv} />27 \mathrm{~Sv}$. See also Fig. $2 \mathrm{~h}$. Note the non-linear color scale for SAT difference.
5, 2019-2051, 2009

\section{Orbital modulation of} AMOC variability

\section{T. Friedrich et al.}

\begin{tabular}{|c|c|}
\hline \multicolumn{2}{|c|}{ Title Page } \\
\hline Abstract & Introduction \\
\hline Conclusions & References \\
\hline Tables & Figures \\
\hline I4 & \\
\hline 4 & $-\mathbf{I}$ \\
\hline Back & Close \\
\hline Full Screen / Esc
\end{tabular}

Printer-friendly Version

Interactive Discussion 


\section{5, 2019-2051, 2009}

\section{Orbital modulation of}

AMOC variability

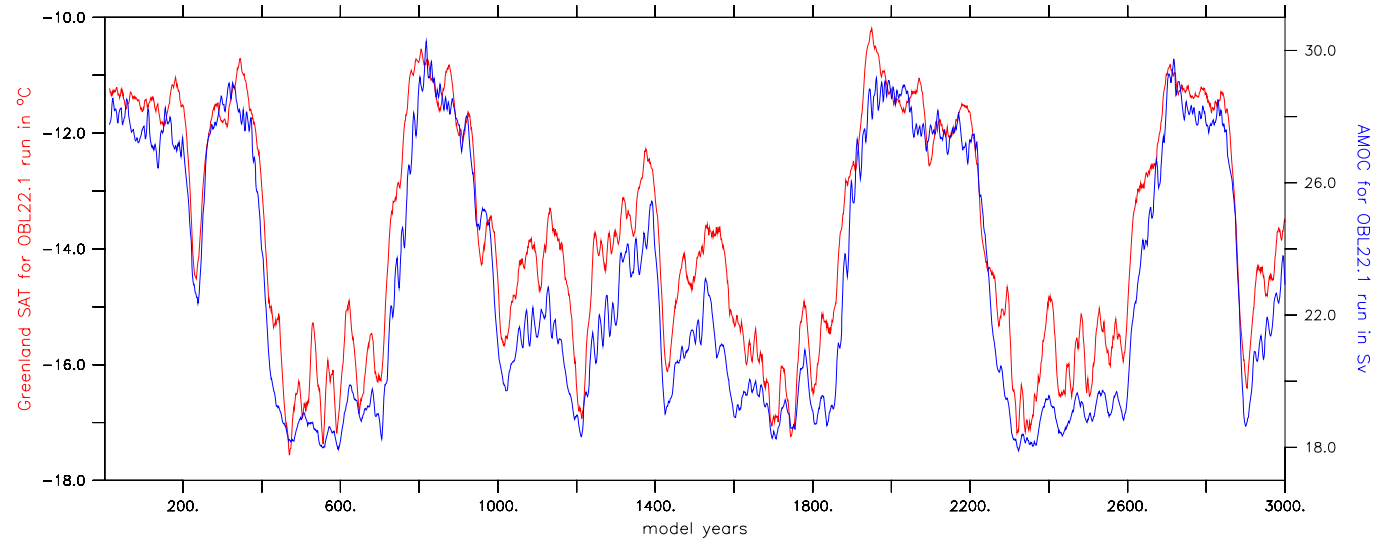

T. Friedrich et al.

Fig. 9. (red) SAT over Greenland in ${ }^{\circ} \mathrm{C}$ for OBL22.1 run. SAT was averaged over $60^{\circ} \mathrm{W}$ to $30^{\circ} \mathrm{W}$ and $60^{\circ} \mathrm{N}$ to $80^{\circ} \mathrm{N}$. (blue) AMOC for OBL22.1 run in Sv. A running mean of 25 years was applied for both timeseries.

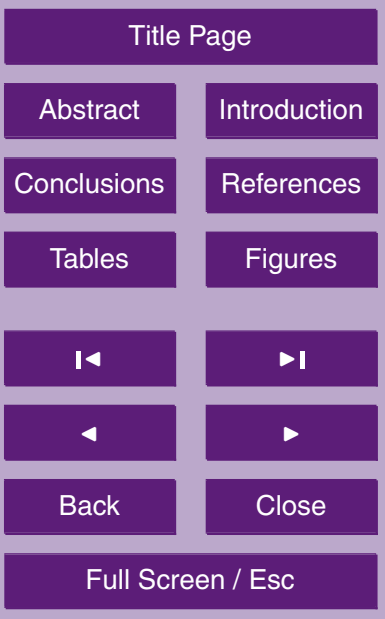

Printer-friendly Version

Interactive Discussion

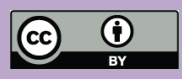



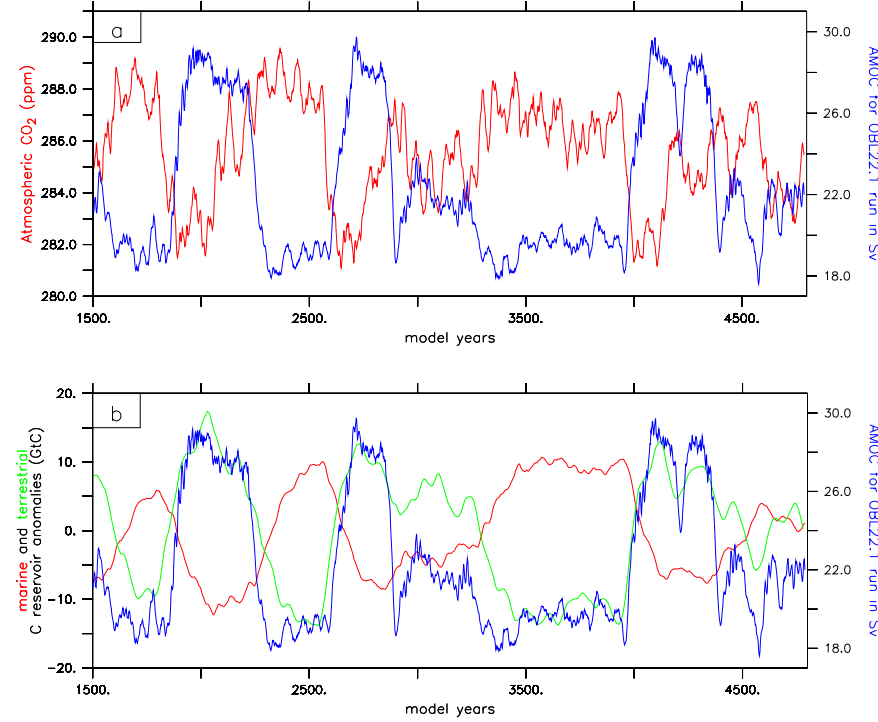

5, 2019-2051, 2009

Orbital modulation of AMOC variability

T. Friedrich et al.
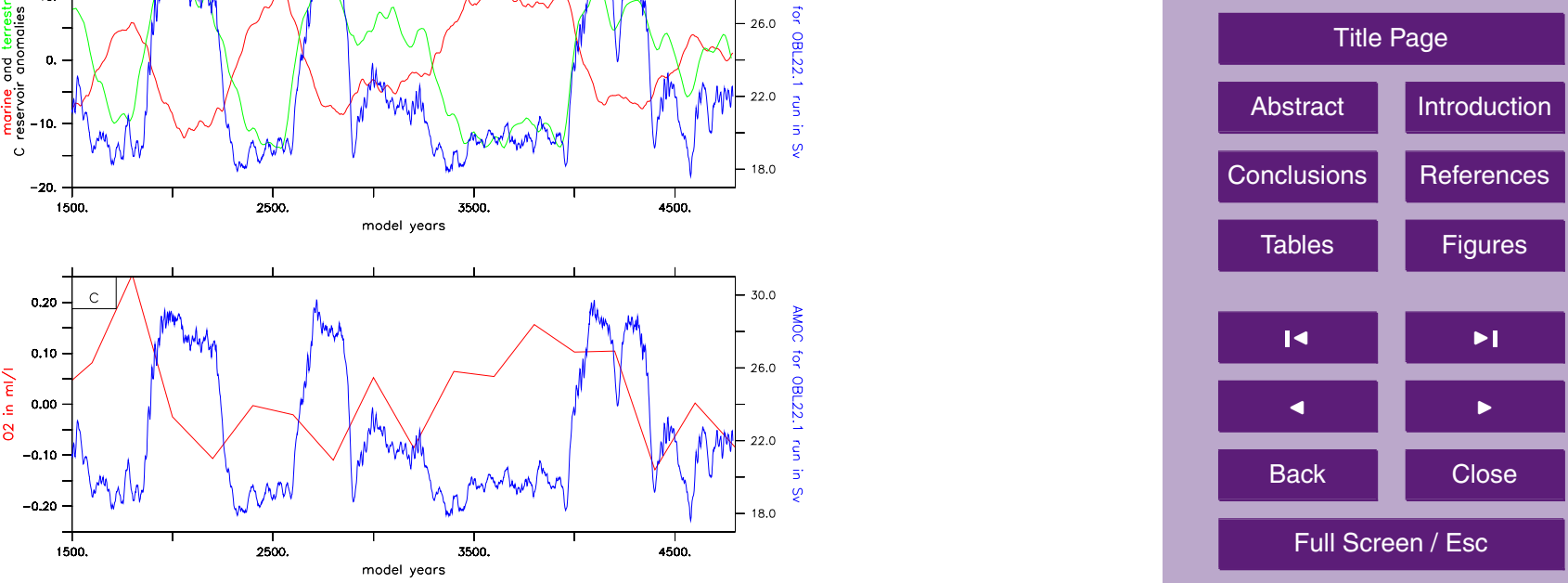

Fig. 10. (a) Atmospheric $\mathrm{CO}_{2}$ content (red) in ppm and AMOC (blue) for OBL22.1 run. (b) Carbon reservoir anomalies for the ocean (red) and the vegetation (green) in GtC and AMOC (blue) for OBL22.1 run in Sv. (c) Oxygen anomalies in $\mathrm{ml} / \mathrm{l}$ (red) averaged over 250-350 m depth along the coast of Baja California and South California and AMOC (blue) for OBL22.1 run in Sv. A running mean of 25 years was applied for all timeseries but Oxygen where output was only available as 200 years mean.

Printer-friendly Version

Interactive Discussion 


\section{5, 2019-2051, 2009}

\section{Orbital modulation of}

AMOC variability

T. Friedrich et al.
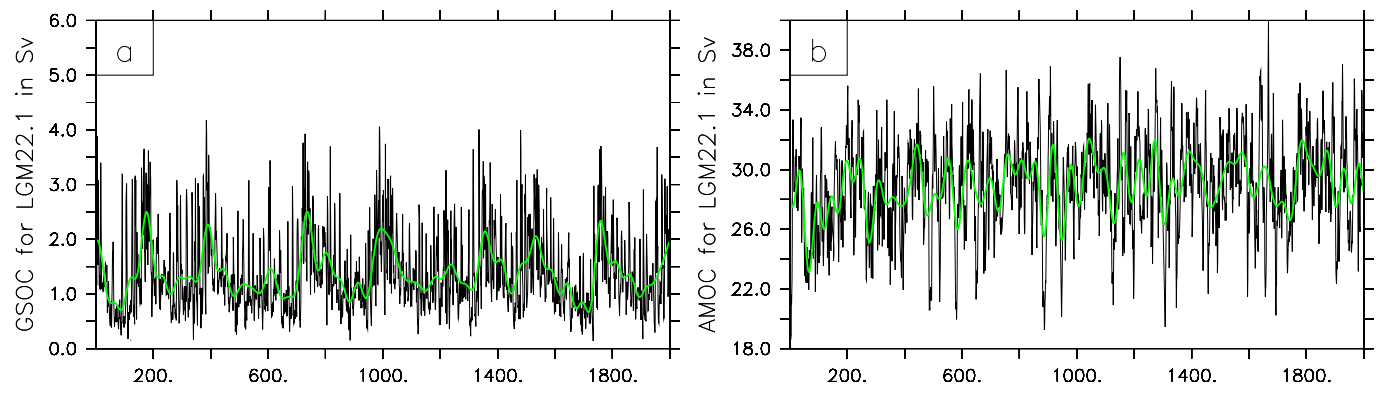

Fig. 11. GSOC (a) and AMOC (b) in Sv for an obliquity of 22.1 but LGM-bathymetry. A low pass filter of 50 years was applied for green lines.
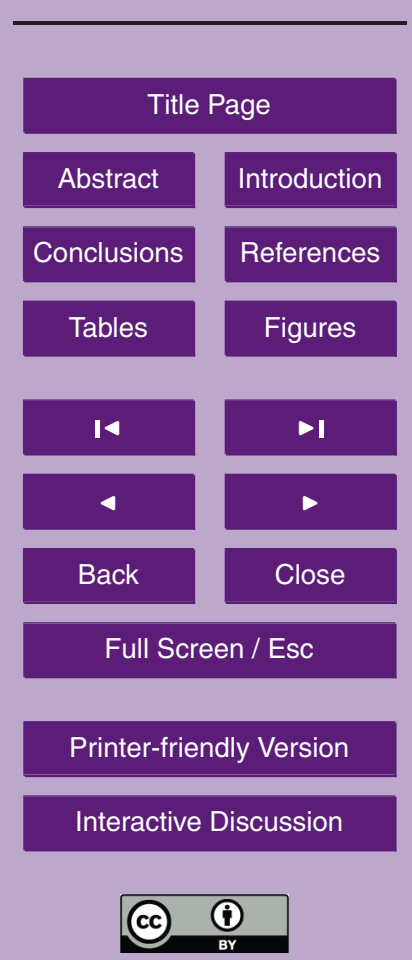